\title{
Figure of Merit for the Thermal Performance of \\ Cementitious Composites Containing Phase Change \\ Materials
}

Alexander M. Thiele ${ }^{1}$, Zhenhua Wei², Gabriel Falzone ${ }^{2}$, Benjamin Young ${ }^{1}$, Narayanan Neithalath ${ }^{4}$, Gaurav Sant ${ }^{2,3}$, and Laurent Pilon ${ }^{1,+}$ University of California, Los Angeles

Henry Samueli School of Engineering and Applied Science

${ }^{1}$ Mechanical and Aerospace Engineering Department

${ }^{2}$ Civil and Environmental Engineering Department

Laboratory for the Chemistry of Construction Materials $\left(\mathrm{LC}^{2}\right)$

${ }^{3}$ California Nanosystems Institute (CNSI)

Arizona State University

${ }^{4}$ School of Sustainable Engineering and the Built Environment

+Corresponding Author: Phone: +1 (310)-206-5598, Fax: +1 (310)-206-2302

Engineering IV

420 Westwood Plaza, Los Angeles, CA 90095-1597

E-mail: pilon@seas.ucla.edu

September 24, 2015 


\section{ABSTRACT}

This paper presents a novel method to quantitatively characterize the thermal performance of composite materials containing phase change materials (PCM) based on a figure of merit we termed the energy indicator. The method features (i) commonly used specimen geometry, (ii) straightforward experimental implementation, and (iii) sensitivity to relevant design parameters including PCM volume fraction, enthalpy of phase change, composite effective thermal conductivity, and specimen dimensions. The experimental method and the concept of energy indicator were demonstrated on PCM-mortar composites using various volume fractions of two commercial microencapsulated PCMs. This was supported by transient two-dimensional heat transfer simulations. The energy indicator was shown to increase linearly with increasing microencapsulated PCM volume fraction and latent heat of fusion and quadratically with the specimen radius. This figure of merit can be used to rapidly screen and select microencapsulated PCM composite materials for energy efficient building or crack-resistant concrete.

Keywords: Phase change materials, microencapsulated, energy efficient building, cracking, cement, characterization 


\section{NOMENCLATURE}

$c_{p, j} \quad$ specific heat of component "j", $\mathrm{J} /(\mathrm{kg} \cdot \mathrm{K})$

D microcapsule diameter, $\mu \mathrm{m}$

$D_{50} \quad$ median outer microcapsule diameter, $\mu \mathrm{m}$

EI energy indicator, ${ }^{\circ} \mathrm{C} \cdot \mathrm{h}$

$E_{r} \quad$ energy flux reduction, \%

$h \quad$ convective heat transfer coefficient, $\mathrm{W} /\left(\mathrm{m}^{2} \cdot \mathrm{K}\right)$

$h_{s f} \quad$ latent heat of fusion, $\mathrm{kJ} / \mathrm{kg}$

$k_{j} \quad$ thermal conductivity of material "j", $\mathrm{W} /(\mathrm{m} \cdot \mathrm{K})$

L cylindrical specimen height, $\mathrm{mm}$

$q_{r}^{\prime \prime}, q_{z}^{\prime \prime} \quad$ heat flux in the $r-$ and $z$ - directions, $\mathrm{W} / \mathrm{m}^{2}$

$r \quad$ radial coordinate direction

$r_{i} \quad$ specimen radius, $\mathrm{mm}$

$r_{o} \quad$ outer cylindrical mold radius, $\mathrm{mm}$

$t \quad$ time, s or h

$T(r, t) \quad$ local temperature, ${ }^{\circ} \mathrm{C}$

$T_{c} \quad$ centerpoint temperature, ${ }^{\circ} \mathrm{C}$

$T_{\infty} \quad$ chamber temperature, ${ }^{\circ} \mathrm{C}$

$T_{\max }, T_{\min }$ maximum and minimum outdoor temperatures, ${ }^{\circ} \mathrm{C}$

$T_{p} \quad$ peak hydration temperature, ${ }^{\circ} \mathrm{C}$

$T_{p c} \quad$ PCM phase change temperature, ${ }^{\circ} \mathrm{C}$

$w / c \quad$ water to cement ratio

z vertical coordinate direction

$z_{b} \quad$ bottom thickness of cylinder mold, $\mathrm{mm}$

\section{Greek symbols}

$\alpha_{j} \quad$ thermal diffusivity of material " $\mathrm{j}$ ", $\mathrm{m}^{2} / \mathrm{s}$

$\Delta T_{p c} \quad$ PCM phase change temperature window, ${ }^{\circ} \mathrm{C}$ 


$\begin{array}{ll}\phi_{j} & \text { volume fraction of material "j" in composite } \\ \rho_{j} & \text { density of material "j", } \mathrm{kg} / \mathrm{m}^{3} \\ \text { Subscripts } & \\ c & \text { refers to core material (PCM) } \\ c+s & \text { refers to core-shell microcapsule } \\ e f f & \text { refers to effective properties } \\ e x p & \text { refers to experimental } \\ f & \text { refers to final } \\ i & \text { refers to initial } \\ l & \text { refers to liquid phase } \\ m & \text { refers to matrix material (cement paste) } \\ s & \text { refers to solid phase or shell material (MF) } \\ P V C & \text { refers to polyvinyl chloride }\end{array}$




\section{Introduction}

The embedment of microencapsulated phase change materials (PCMs) has been shown to be an effective means of enhancing the effective thermal inertia of concrete [1-5]. PCMs store and release heat by undergoing reversible phase transitions between the solid and liquid states [6]. The associated latent heat greatly increases the volumetric thermal storage of traditional building materials, which otherwise only demonstrate sensible heat storage and release [7]. Recently, the incorporation of PCMs has also been demonstrated as a means to mitigate thermal cracking in restrained concrete elements including pavement and bridge decks [8].

Cementitious composites containing PCMs (henceforth referred to as PCM-mortar composites) utilized for reducing building energy needs or for mitigating thermal cracking may include a variety of cement compositions and microencapsulated PCMs with a wide range of thermophysical properties. In both applications, the amount and thermal properties of PCM within the composite must be chosen to achieve the desired augmentation in thermal energy storage and/or decrease in effective thermal conductivity. In spite of significant research, performance-based design criteria have not been defined. For example, typical experimental research highlights that thermal performance of PCM-composite materials improves as PCM is added, but does not quantify how much a unit increase in PCM volume fraction alters such performance. To address these limitations, this study introduces a novel, and easy to implement, experimental method to quantitatively compare the thermal behavior of PCM-mortar composites with various constituent volume fractions and thermal properties.

\section{Background}

\subsection{Performance metrics of PCM-composite materials}

Evola et al. [9] proposed two metrics to quantify the effectiveness of gypsum wallboards containing PCM for improving the thermal comfort of building occupants during summer months. They offered two other metrics to quantify how often and to what extent the PCM 
latent heat storage was utilized. First, the intensity of thermal discomfort for overheating $\operatorname{ITD}_{\text {over }}$ (in ${ }^{\circ} \mathrm{C} \cdot \mathrm{h}$ ) was defined as the time integral, over the room occupancy period, of the difference between the operative room temperature and the upper limit of thermal comfort temperature range. Second, the frequency of thermal comfort FTC was defined as the percentage of time, within the room occupancy period, during which the operative room temperature fell within the thermal comfort temperature range. Third, the frequency of activation FA was defined as the percentage of time, over an entire day or a given occupancy period, during which the PCM was experiencing phase change. Finally, the PCM energy storage efficiency $\eta_{P C M}$ was defined as the ratio of the thermal energy stored by the PCM, over one day, to the PCM latent heat of fusion. In order to maximize the thermal comfort within the room, ITD should be minimized and FTC should be maximized. Additionally, FA and $\eta_{P C M}$ should both be maximized in order to take full advantage of the PCM.

Castell and Farid [10] tested the methodology proposed by Evola et al. [9] using experimental measurements of the air temperature within enclosures made of concrete, brick, or timber walls containing PCM and located in Spain or New Zealand. They proposed two modifications to the metrics proposed by Evola et al. [9]: (i) ITD could include periods when the indoor temperature fell below the thermal comfort temperature range ITD $_{\text {under }}$, such as at night time so that ITD $=\mathrm{ITD}_{\text {over }}+\mathrm{ITD}_{\text {under }}$ and (ii) FTC could be evaluated over the entire day rather than only during the occupancy period. With these modifications, Castell and Farid [10] evaluated the thermal comfort of the enclosures over three occupancy profiles: (i) between 9:00 am and 5:00 pm, (ii) between 6:00 pm and 8:00 am, and (iii) over the entire day. For all types of enclosures considered, ITD decreased as PCM was added to the wall and also depended strongly on the occupancy profile. In general, the FTC increased as PCM was added to the wall. Lastly, the FA provided contradictory and misleading indication of PCM performance. Castell and Farid [10] concluded that the ITD was the most relevant indicator suggested by Evola et al. [9] and that it should be evaluated during periods both when the indoor temperature exceeded $\left(\operatorname{ITD}_{\text {over }}\right)$ and when it fell below (ITD under $)$ the thermal comfort temperature range. 
Overall, these metrics were useful to assess the thermal comfort within large-scale PCMbuilding envelopes subjected to realistic operating conditions. However, characterization using these metrics is costly both in terms of time and materials. In fact, they cannot be readily applied to a simple experimental setup to assess the thermal performance of novel PCM-composite materials. As such, there is a need for metrics to compare the attractiveness of different PCM-composite materials using straightforward experimental tests on relatively small samples. Such performance metrics should be sensitive to relevant design parameters such as the volume fractions and thermal properties of constituent materials, the phase change properties of the PCM, and the sample dimensions.

\subsection{Numerical modeling of phase change in three-component composites}

Recently, we showed that transient heat transfer through three-component composite materials consisting of ordered monodisperse PCM microcapsules and of either monodisperse or polydisperse PCM microcapsules randomly distributed in a continuous matrix can be accurately described by simulating a homogeneous material with some effective thermal conductivity and heat capacity $[5,11]$. The effective thermal conductivity $k_{\text {eff }}$ of the threecomponent composites was predicted by the Felske model [12]. On the other hand, their

effective volumetric heat capacity $\left(\rho c_{p}\right)_{\text {eff }}(T)$ was estimated based on simple thermodynamic arguments [5]. The effective thermal conductivity and effective volumetric heat capacity depended only on the constituent phase properties and on their volume fractions and were independent of the microcapsule spatial arrangement and polydispersity, as established numerically $[5,11]$.

Two of the most common methods of simulating phase change are the enthalpy method and the heat capacity method [13]. These methods involve solution of the transient heat conduction equation expressed in terms of temperature and either enthalpy or specific heat, respectively [13]. Lamberg et al. [14] concluded that both of these methods provided a "good estimation" of melting and freezing processes and that the heat capacity method agreed more closely with experimental data. Kalagasidis [15] modelled phase change using 
the effective heat capacity method and showed that the numerically predicted air and wall surface temperatures within a room with PCM composite walls agreed well with experimental measurements. According to the heat capacity method for simulating phase change, the volumetric heat capacity of the PCM $\left(\rho c_{p}\right)_{c}(T)$ can be defined as a step function in terms of temperature with a rectangular peak of (i) width $\Delta T_{p c}$ centered around the phase change temperature denoted by $T_{p c}$ and (ii) enclosed area equal to the PCM latent heat of fusion $h_{s f}[5]$. Thus, the effective volumetric heat capacity was also temperature-dependent and expressed as [5],

$$
\left(\rho c_{p}\right)_{e f f}(T)=\left\{\begin{array}{lll}
\left(\rho c_{p}\right)_{e f f, s} & \text { for } \quad T<T_{p c}-\Delta T_{p c} / 2 \\
\left(\rho c_{p}\right)_{e f f, s}+\phi_{c} \frac{\rho_{c, s} h_{s f}}{\Delta T_{p c}} & \text { for } \quad T_{p c}-\Delta T_{p c} / 2 \leq T \leq T_{p c}+\Delta T_{p c} / 2 . \\
\left(\rho c_{p}\right)_{e f f, l} & \text { for } \quad T>T_{p c}+\Delta T_{p c} / 2
\end{array}\right.
$$

Here, $T_{p c}, \Delta T_{p c}$, and $h_{s f}$ represent the phase change temperature, temperature window, and latent heat of fusion, respectively. The effective volumetric heat capacities $\left(\rho c_{p}\right)_{e f f, s}$ and $\left(\rho c_{p}\right)_{e f f, l}$ of the microencapsulated PCM-concrete wall correspond to situations when the PCM is solid and liquid, respectively. If the PCM is unmelted, then $\left(\rho c_{p}\right)_{e f f, s}=\phi_{c}\left(\rho c_{p}\right)_{c, s}+$ $\phi_{s}\left(\rho c_{p}\right)_{s}+\left(1-\phi_{c}-\phi_{s}\right)\left(\rho c_{p}\right)_{m}$ where $\left(\rho c_{p}\right)_{c, s}$ is the volumetric heat capacity of solid PCM. The volumetric heat capacities of the solid and fully melted PCM were assumed to be equal so that $\left(\rho c_{p}\right)_{c, s}=\left(\rho c_{p}\right)_{c, l}$ and $\left(\rho c_{p}\right)_{e f f, s}=\left(\rho c_{p}\right)_{e f f, l}$. Indeed, the volumetric heat capacity of commercial organic PCM does not differ significantly between the solid and the liquid phases.

Alternatively, the PCM specific heat $c_{p, c}(T)$ can be expressed as a Gaussian function of temperature as,

$$
c_{p, c}(T)=c_{p, c, s}+\frac{4 h_{s f}}{\sqrt{2 \pi} \Delta T_{p c}} e^{-0.5\left(\frac{4\left(T-T_{p c}\right)}{\Delta T_{p c}}\right)^{2}} .
$$

Note that this representation resembles more closely the typical temperature response of PCMs. Here, the PCM specific heat $c_{p, c}(T)$ reaches its maximum value at the phase change temperature $T_{p c}$. The area enclosed by Equation (2) and the line $c_{p, c}=c_{p, c, s}$ represents the 
latent heat of fusion $h_{s f}$. Furthermore, expressing $c_{p, c}(T)$ using Equation (2) indicates that $68 \%$ and $95 \%$ of the latent heat is stored and released within the temperature ranges $T_{p c} \pm$ $\Delta T_{p c} / 4$ and $T_{p c} \pm \Delta T_{p c} / 2$, respectively. Note that the heat capacity method and the Gaussian approximation are idealized representations of the PCM specific heat. In reality, PCMs exhibit superheating and subcooling during melting and freezing, respectively, delaying phase

change and causing hysteresis in $c_{p_{c}}(T)$. Additionally, commercially available PCMs may contain constituents with different molecular weights, resulting in multiple specific heat peaks in a single heating-cooling cycle [16].

The present study describes an experimental method, supported by physical modeling, to quantitatively characterize the thermal behavior of PCM-mortar composites based on a novel figure of merit termed the energy indicator. The method aims to capture the cumulative effects of microencapsulated PCM on the effective thermal conductivity and on the sensible and latent thermal energy storage of microencapsulated PCM-mortar composites. Advantages of this method include (i) specimen geometry commonly used to measure experimentally the mechanical properties of cementitious materials, (ii) straightforward experimental implementation, and (iii) sensitivity to relevant design parameters such as PCM volume fraction and thermal properties.

\section{Materials and methods}

\subsection{Material synthesis}

In the present study, two types of microencapsulated PCM (MPCM24D and MPCM32D, Microtek Laboratories Inc.) were used, featuring melting temperatures around $24^{\circ} \mathrm{C}$ and $32^{\circ} \mathrm{C}$, respectively. Each consisted of a polymeric melamine-formaldehyde (MF) shell surrounding a paraffinous core.

Cementitious composites containing these microencapsulated PCMs were fabricated using a commercially available Type I/II ordinary portland cement (OPC) and deionized (DI) water. Composite specimens were formulated as mortars, wherein the microencapsulated 
PCM occupied a volume fraction $\phi_{c+s}=\phi_{c}+\phi_{s}$ ranging from 0.0 to 0.3 in 0.1 increments. The desired microencapsulated PCM volume fraction $\phi_{c+s}$ was achieved by measuring and adding the required mass based on the microencapsulated PCM density $\rho_{c+s}$. The mortars were prepared as described by ASTM C305 [17] at a water to cement ratio $w / c=0.45$ on a mass basis. To enhance the fluidity of fresh mortars, a commercially available water-reducing admixture (Glenium 7500, BASF Corporation) was added at a dosage ranging from 0-2\% of the cement mass. The mortar formulations were allowed to cure in sealed conditions for 7 days prior to thermal cycling to limit the influence of exothermic cement hydration reactions on the measured temperatures. Then, the sealed specimens were exposed to thermal cycles. The thermal properties of cementitious specimens may change as a function of their internal moisture content and temperature. However, since the specimens were cured in sealed conditions, the pores were assumed to be near liquid saturation and remain in that state over the course of the experiment. It should be noted that Kim et al. [18] showed that the thermal conductivity of wet and dry cement paste with a given w/c varied within less than 20\%. Thus, under practical conditions, moisture state is expected to have little effect on the thermal conductivity of the cement paste and the quantified energy indicator.

\subsection{Specimens}

The PCM-mortar composites previously described were cast into a cylindrical PVC mold with wall thickness of about $2 \mathrm{~mm}$. Figure 1 shows a schematic of the cylindrical specimen with height $L=152.4 \mathrm{~mm}$ and cylindrical mold featuring inner $d_{i}$ and outer $d_{o}$ diameters of 76.2 and $79.8 \mathrm{~mm}$, respectively. This geometry was chosen for the ease in (i) casting various cementitious formulations and (ii) imposing one-dimensional (1D) heat transfer along the specimen's radial direction. Thermocouples were embedded along the cylinders' axes at 3.81 and $7.62 \mathrm{~cm}$ from the bottom of the cast specimen. These locations were selected to ensure that the temperature measurements would not be influenced by the air gap between the top of the specimen and the lid sealing the container. They were also selected to verify experimentally that $1 \mathrm{D}$ heat transfer prevailed. The thermocouples were placed by threading them 
through a hollow acrylonitrile butadiene styrene (ABS) plastic rod oriented perpendicular to the axis of the cylinder prior to pouring the mortar into the mold. To ensure proper thermal contact between the thermocouple element and the cementitious formulation, a $3 \mathrm{~mm}$ diameter hole was drilled perpendicular to the axis of the hollow ABS plastic rod, enabling the mortar to intrude into the cavity and surround the thermocouple. The center of each plastic rod, coinciding with the drilled hole and the thermocouple junction, was located at the axis of the cylindrical mold.

\subsection{Material characterization}

The particle size distribution (PSD) of the microencapsulated PCM was measured using a static light scattering particle analyzer (LS13-320, Beckman Coulter) operating at a wavelength of $750 \mathrm{~nm}$. As PCM microcapsules tend to agglomerate, they were first dispersed into individual particles before characterization. To do so, PCM microcapsules were placed in isopropanol and subjected to vibrations in an ultrasonic bath prior to PSD measurement. As a significant quantity of PCM microcapsules were expected to have small diameters $(D<7.5$ $\mu \mathrm{m})$, the Lorenz-Mie theory for light scattering by spherical particles was used for analysis. The refractive indices of isopropanol and PCMs at $750 \mathrm{~nm}$ were respectively taken as $1.37+0.00 i[19]$ and $1.53+0.00 i[20]$.

The density of cement paste samples of the same formulation described in Section 3.1 was determined based on volume and mass measurements, compliant with ASTM C138 [21]. The density $\rho_{c+s}$ of each microencapsulated PCM was reported by the manufacturer as 900 $\mathrm{kg} / \mathrm{m}^{3}$. The specific heat of cement paste was determined by differential scanning calorimetry (DSC 8500, Perkin Elmer) using the dynamic method. Similarly, the phase change properties

of the microencapsulated PCMs including phase transition temperatures, heat capacity, and enthalpy of phase change were also determined by DSC. Test samples of approximately $5 \mathrm{mg}$ of microencapsulated PCM contained in aluminum pans were subjected to a temperature cycle ranging from -45 to $45^{\circ} \mathrm{C}$ for MCPM24D and -40 to $60^{\circ} \mathrm{C}$ for MPCM32D at temperature ramp rates between 1 and $10^{\circ} \mathrm{C} / \mathrm{min}$. The $\mathrm{DSC}$ was calibrated in terms of its temperature and 
heat flow measurements using zinc and indium as calibration standards. The heat capacity of the PCM was measured using a three-curve method compliant with ASTM E1269 [22] wherein sapphire was used as the heat capacity reference [23].

The measured core-shell specific heat capacity $c_{p, c+s}(T)$ was used to define the core-shell volumetric heat capacity as

$$
\left(\rho c_{p}\right)_{c+s}(T)=\phi_{c / s}\left(\rho c_{p}\right)_{c}(T)+\left(1-\phi_{c / s}\right)\left(\rho c_{p}\right)_{s}
$$

where the volume fraction of core with respect to shell material is defined as $\phi_{c / s}=\phi_{c} /\left(\phi_{c}+\right.$ $\left.\phi_{s}\right)$. It was taken as 0.15 , based on manufacturer specification.

\subsection{Experimental apparatus}

The PCM-mortar composite specimens synthesized according to the protocol previously described were placed in a freeze-thaw chamber (TH024, Darwin Chambers Company). Temperature evolution within specimens subjected to an ambient temperature $T_{\infty}(t)$ was measured using solid 24 gauge Type T (copper-constantan) thermocouple wires in FEP insulation. These thermocouples were connected to 16-channel input modules (NI 9213, National Instruments) in a CompactDAQ chassis (cDAQ-9178, National Instruments). Each input module provided built-in cold-junction compensation. Data acquisition was facilitated by a PC running LabVIEW 2014. Thermocouple calibration was performed using a refrig-

erating/heating circulating water bath (AD28R-30-A11B, PolyScience). Each thermocouple junction was allowed to equilibrate in the water bath for 30 minutes at $5^{\circ} \mathrm{C}$ intervals within the range $4-60^{\circ} \mathrm{C}$ and the voltage was measured in $60 \mathrm{~s}$ intervals. Temperature was plotted as a linear function of voltage for each thermocouple.

\subsection{Experimental procedure}

After the specimens were cured for seven days, they were placed within a freeze-thaw chamber and subjected to a temperature profile consisting of three cycles over a temperature range of $5-45^{\circ} \mathrm{C}$. This range was selected based on the DSC results (Figure 4) such that the 
PCM experienced nearly complete melting/solidification during each cycle. The applied temperature ramp rate was successively 20,5 , and $2^{\circ} \mathrm{C} / \mathrm{h}$ over three consecutive cycles. Isothermal holds were imposed for 6 hours at the minimum and maximum temperatures during each cycle and for 24 hours at $T_{\infty}=25^{\circ} \mathrm{C}$ between cycles to ensure that the specimen reached thermal equilibrium with the chamber before starting a new cycle.

\subsection{Experimental uncertainty}

The uncertainty in median particle diameter was less than $3.5 \%$ based on three replicate measurements. The uncertainty in the microencapsulated PCM volume fraction $\phi_{c+s}$ was estimated to be less than $0.13 \%$ based on the precision of the balance used in the mass measurements. The temperature of the environmental chamber was controlled within $\pm 0.2^{\circ} \mathrm{C}$, based on manufacturer specification. Throughout the chamber, temperature was expected to vary by no more than $1^{\circ} \mathrm{C}$. On completion of the thermocouple calibration procedure, the maximum uncertainty in the measured temperatures was on the order of $\pm 1^{\circ} \mathrm{C}$. The uncertainty in the axial and radial locations of the thermocouples were on the order of \pm 1.5 $\mathrm{mm}$.

\section{Analysis}

\subsection{Schematic and assumptions}

Figure 2 illustrates the two-dimensional (2D) domain numerically simulated. By virtue of symmetry, it corresponds to a quarter of the cylindrical PVC mold used experimentally to synthesize microencapsulated PCM-mortar composite and shown in Figure 1.

To make the problem mathematically tractable, the following assumptions were made: (1) The PCM-mortar composite behaved as a homogeneous and isotropic medium with some effective thermal conductivity $k_{e f f}$ and effective volumetric heat capacity $\left(\rho c_{p}\right)_{e f f}$. All thermal properties were constant except for the temperature-dependent specific heat to account for phase change. (3) 2D axysymmetric transient heat conduction prevailed. (4) 
There was no heat generation in the PCM-mortar composite. (5) Thermal contact resistances between the PVC container and the PCM-mortar composite and between the mortar and the microencapsulated PCM were negligible. (6) The side and bottom of the PVC container were subjected to convective heat transfer with uniform and constant heat transfer coefficient $h$ and time-dependent imposed chamber temperature $T_{\infty}(t)$.

\subsection{Governing equations}

Under the above assumptions, the local temperatures in the PCM-mortar composite and PVC mold at time $t$ and location $\mathbf{r}=\langle r, z\rangle$, denoted by $T(\mathbf{r}, t)$ and $T_{P V C}(\mathbf{r}, t)$, were governed by the $2 \mathrm{D}$ transient heat conduction equation expressed in cylindrical coordinates as [24],

$$
\begin{aligned}
\frac{1}{\alpha_{e f f}(T)} \frac{\partial T}{\partial t} & =\frac{1}{r} \frac{\partial T}{\partial r}\left(r \frac{\partial T}{\partial r}\right)+\frac{\partial^{2} T}{\partial z^{2}} \text { and } \\
\frac{1}{\alpha_{P V C}} \frac{\partial T_{P V C}}{\partial t} & =\frac{1}{r} \frac{\partial T_{P V C}}{\partial r}\left(r \frac{\partial T_{P V C}}{\partial r}\right)+\frac{\partial^{2} T_{P V C}}{\partial z^{2}}
\end{aligned}
$$

where $\alpha_{e f f}(T)=k_{e f f} /\left(\rho c_{p}\right)_{e f f}(T)$ and $\alpha_{P V C}=k_{P V C} /\left(\rho c_{p}\right)_{P V C}$ are the effective thermal diffusivity of the PCM-mortar composite and of the PVC mold, respectively. Here, the effective thermal conductivity $k_{\text {eff }}$ was determined using the Felske model [12] and the effective volumetric heat capacity $\left(\rho c_{p}\right)_{\text {eff }}(T)$ was estimated using basic thermodynamic arguments, as discussed in Section 2.2. The effective volumetric heat capacity $\left(\rho c_{p}\right)_{e f f}(T)$ was expressed in terms of microencapsulated PCM volume fraction $\phi_{c+s}=\phi_{c}+\phi_{s}$ and core-shell volumetric heat capacity $\left(\rho c_{p}\right)_{c+s}(T)$ given by Equation (3). In order to compare numerical predictions with experimental measurements, the measured specific heat $c_{p, c+s}(T)$ of the microencapsulated PCM was used in numerical simulations, including the hysteresis observed during the melting and freezing cycle. For subsequent parametric study, the volumetric heat capacity of the PCM $\left(\rho c_{p}\right)_{c}(T)$ was defined as a step or a Gaussian function of temperature given by Equations (1) and (2), respectively [5]. 


\subsection{Initial and boundary conditions}

The initial temperature was assumed to be uniform throughout the microencapsulated PCMmortar composite and the PVC mold and equal to $T_{i}$, i.e.,

$$
T(r, z, 0)=T_{i} \quad \text { and } \quad T_{P V C}(r, z, 0)=T_{i} .
$$

Convective heat transfer was imposed at the outer $\left(r=r_{o}\right)$ and bottom $\left(z=z_{b}\right)$ surfaces of the PVC mold with a time-dependent ambient temperature $T_{\infty}(t)$ such that,

$$
\begin{aligned}
& -k_{P V C} \frac{\partial T_{P V C}}{\partial r}\left(r_{o}, z, t\right)=h\left[T_{P V C}\left(r_{o}, z, t\right)-T_{\infty}(t)\right] \text { and } \\
& -k_{P V C} \frac{\partial T_{P V C}}{\partial z}\left(r, z_{b}, t\right)=h\left[T_{P V C}\left(r, z_{b}, t\right)-T_{\infty}(t)\right]
\end{aligned}
$$

where $h$ is the convective heat transfer coefficient between the PVC mold and the freeze-thaw chamber.

The heat flux was continuous at the radial $\left(r=r_{i}\right)$ and bottom $(z=0)$ PVC/PCMmortar composite interfaces, i.e.,

$$
\begin{aligned}
-k_{P V C} \frac{\partial T_{P V C}}{\partial r}\left(r_{i}, z, t\right) & =-k_{e f f} \frac{\partial T}{\partial r}\left(r_{i}, z, t\right) \text { and } \\
-k_{P V C} \frac{\partial T_{P V C}}{\partial r}(r, 0, t) & =-k_{e f f} \frac{\partial T}{\partial r}(r, 0, t) .
\end{aligned}
$$

Finally, by virtue of symmetry, the heat flux through the centerline $r=0 \mathrm{~m}$ and through the $z=L / 2$ plane was zero, i.e.,

$$
\frac{\partial T}{\partial r}(0, z, t)=\frac{\partial T_{P V C}}{\partial r}(0, z, t)=\frac{\partial T}{\partial z}(r, L / 2, t)=\frac{\partial T_{P V C}}{\partial z}(r, L / 2, t)=0 .
$$

\subsection{Constitutive relationships}

Table 1 summarizes the density, thermal conductivity, and specific heat of the mold, PCM, shell, and matrix corresponding to those of PVC, commercial paraffin-based PCM [25], melamine-formaldehyde (MF) [26], and cement paste [27], respectively. The density of cement paste samples $\rho_{m}$ with w/c of 0.45 was measured as described in Section 3.3 to be 1965 $\mathrm{kg} / \mathrm{m}^{3}$. According to the Microtek MPCM24D datasheet [25], the microcapsules contained about 85 mass \% PCM. Then, the densities of the paraffin PCM and of the MF shell (Table 
1) were used to determine the core and shell volume fractions corresponding to a given coreshell volume fraction $\phi_{c+s}$. The effective thermal conductivity $k_{e f f}$ and effective volumetric heat capacity $\rho c_{p}(T)_{e f f}$ of the PCM-mortar composites both decreased nearly linearly with microencapsulated PCM volume fraction $\phi_{c+s}$ increasing from 0.0 to 0.3 . Thus, the thermal resistance increased and the sensible heat storage capacity decreased slightly with the addition of PCM.

Finally, the experimentally measured temperature was compared to the numerically predicted temperature at the centerpoint of a plain cement paste specimen subjected to heating and cooling cycles with a convective heat transfer coefficient $h$ ranging from $10-30 \mathrm{~W} /\left(\mathrm{m}^{2} \cdot \mathrm{K}\right)$ in $5 \mathrm{~W} /\left(\mathrm{m}^{2} \cdot \mathrm{K}\right)$ increments. The average relative error between the numerically predicted and experimentally measured centerpoint temperature was less than $2.5 \%$ for $h=20 \mathrm{~W} /\left(\mathrm{m}^{2} \cdot \mathrm{K}\right)$ during both heating and cooling (see Supplementary material). Therefore, $h$ was taken as $20 \mathrm{~W} /\left(\mathrm{m}^{2} \cdot \mathrm{K}\right)$ in simulations of PCM-mortar composites for comparison with experimental measurements.

\subsection{Method of solution}

The governing Equation (4) along with the initial and boundary conditions given by Equations (6) to (9) were solved using the commercial finite element solver COMSOL Multiphysics 4.3. Numerical convergence was considered to be reached when the maximum relative difference in the centerpoint temperature $T_{c}(r=0, z)$ was less than $1 \%$ when reducing the mesh size or time step by a factor of 2 . In practice, converged solutions were obtained by imposing a time step of $240 \mathrm{~s}$. Figure 2 shows the mesh consisting of triangular elements on an unstructured grid. The minimum mesh element edge size and maximum growth rate for converged solutions were $23.1 \mu \mathrm{m}$ and 1.3, respectively. The number of finite elements needed to obtain a converged solution was 876 . 


\subsection{Data processing}

The temporal evolution of the temperature at the centerpoint $(0, L / 2)$ of the PCM-mortar

composite $T_{c, \text { comp }}(t)=T_{\text {comp }}(0, L / 2, t)$ and within the plain cement paste $T_{c, m}(t)=T_{m}(0, L / 2, t)$ were compared during a given melting and freezing cycle. They were nearly identical when the PCM was entirely solid or liquid. However, they expectedly diverged when the PCM was undergoing phase transition. The energy indicator $E I$ (in ${ }^{\circ} \mathrm{C} \cdot \mathrm{h}$ ) was defined as a metric to quantify the thermal performance of microencapsulated PCM-mortar compared with plain cement paste and was expressed as,

$$
E I=\int_{t_{i}}^{t_{f}}\left|T_{c, c o m p}(t)-T_{c, m}(t)\right| d t
$$

where the times $t_{i}$ and $t_{f}$ were defined as the earliest points where $T_{c, \text { comp }}(t)$ and $T_{c, m}(t)$ differed by more (for $t_{i}$ ) or less (for $t_{f}$ ) than a small arbitrary value, taken as $0.15^{\circ} \mathrm{C}$, at the beginning or end of a phase change process, respectively. The energy indicator EI is graphically represented by the area enclosed by the temperature curves $T_{c, \text { comp }}(t)$ of PCMmortar and $T_{c, m}(t)$ of plain cement paste specimens during phase change.

The criteria for $t_{i}$ and $t_{f}$ were selected for two reasons: (i) to integrate only over the times corresponding to phase change, since there is no effect of latent heat storage outside of this time period and (ii) to have a reference time from where integration could be applied. Criteria for integration bounds were varied between 0.1 and $0.5^{\circ} \mathrm{C}$ to determine the smallest suitable bounds within which $T_{c, \text { comp }}(t)$ and $T_{c, m}(t)$ converged. When the criteria was too small, many $T_{c, \text { comp }}(t)$ and $T_{c, m}(t)$ curves did not converge due to noise in the thermocouple signal and systematic experimental uncertainty and $E I$ could not be determined. On the other hand, large criteria led to significant underestimation of $E I$, particularly at slower temperature ramp rates. Therefore, a balance must be struck when selecting criteria used to define $t_{i}$ and $t_{f}$ for determining $E I$. 


\subsection{Validation}

In order to verify that the centerpoint temperature was independent of the thermal effects of the ends of the specimen, the experimentally measured temperature at 3.81 and $7.62 \mathrm{~cm}$ from the bottom of the cement paste specimens without and with microencapsulated PCM was compared. The measured temperature at the two locations agreed within experimental uncertainty for most of the test period. It differed by more than $2^{\circ} \mathrm{C}$ only in some cases and during periods when the PCM was undergoing phase change and never for more than a $1 \mathrm{~h}$ duration. The temperature difference during phase change was greater in specimens containing larger microencapsulated PCM volume fractions $\phi_{c+s}$ and when they were subjected to faster heating and cooling ramp rates. The numerically predicted temperature at 3.81 and $7.62 \mathrm{~cm}$ from the bottom of cement paste specimens without and with microencapsulated PCM was nearly identical at all times.

\section{Results and discussion}

\subsection{Material characterization}

Figure 3 shows the measured PSD of microencapsulated PCMs MPCM24D and MPCM32D. The median microcapsule diameters for MPCM24D and MPCM32D were respectively $D_{50}=$ $20.0 \mu \mathrm{m}$ and $D_{50}=15.2 \mu \mathrm{m}$, both within the ranges reported by the manufacturer. As noted by the manufacturer, each PCM microcapsule was comprised of 85 - 90 mass \% PCM core and 10 - 15 mass \% shell. The median shell thickness ranged from 0.7 - 1.1 $\mu \mathrm{m}$ for MPCM24D and from $0.5-0.8 \mu \mathrm{m}$ for MPCM32D.

Figure 4a plots the measured specific heat $c_{p, c+s}$ of MPCM24D as a function of temperature with temperature ramp rate of $1^{\circ} \mathrm{C} / \mathrm{min}$. The peak melting temperature was $24^{\circ} \mathrm{C}$, while the peak solidification temperature was $19^{\circ} \mathrm{C}$. In addition, multiple peaks can be observed in the measured specific heat as a function of temperature. This can be attributed to the presence of constituents (potentially impurities) with different molecular weights. Indeed, the desired phase change temperature of commercial paraffin PCMs is achieved by blending 
constituents with different alkane chain lengths [16]. The latent heat of fusion $h_{s f}$, averaged between melting and solidification cycles over three measurements between -45 and $45^{\circ} \mathrm{C}$, was determined to be $160.6 \pm 0.6 \mathrm{~kJ} / \mathrm{kg}$. This was larger than the manufacturer-reported value of $124.4 \mathrm{~kJ} / \mathrm{kg}$. Note, however, that the enthalpy corresponding to the main specific heat peak between 10 and $25^{\circ} \mathrm{C}$ was measured to be about $124 \mathrm{~kJ} / \mathrm{kg}$.

Similarly, Figure $4 \mathrm{~b}$ plots the measured specific heat $c_{p, c+s}$ of MPCM32D as a function of temperature with a temperature ramp rate of $1^{\circ} \mathrm{C} / \mathrm{min}$. The peak melting temperature was about $32^{\circ} \mathrm{C}$, while the peak solidification temperature was about $28^{\circ} \mathrm{C}$. MPCM32D exhibited only two distinct peaks in $c_{p, c+s}(T)$, suggesting that there were fewer constituents than in MPCM24D. Here also, phase transition occurred over a very wide temperature range during melting and solidification. Slight hysteresis was observed in the specific heat of both MPCM32D and MPCM24D. This was attributed to the lack of heterogeneous nucleation sites

for PCM solidification within the small microcapsules [28]. The latent heat of fusion $h_{s f}$ of MPCM32D, averaged between melting and solidification cycles over three measurements between -40 and $60^{\circ} \mathrm{C}$, was determined to be $164.4 \pm 0.6 \mathrm{~kJ} / \mathrm{kg}$.

The microencapsulated PCM specific heat was also measured using DSC temperature ramp rates of 2,5 , and $10^{\circ} \mathrm{C} / \mathrm{min}$. The difference between the peak melting and solidification temperatures increased and the main specific heat peaks grew wider as the temperature ramp rate increased. However, the measured latent heat of fusion did not strongly depend on the DSC ramp rate. This was consistent with the findings of Albright et al. [29].

\subsection{Experimental/numerical comparison}

\subsubsection{Centerpoint temperature}

Figure 5 plots the experimentally measured centerpoint temperature $T_{c}(t)$ as a function of time for specimens made of cement paste without and with MPCM32D with a volume fraction $\phi_{c+s}$ of $0.1,0.2$, or 0.3 . It also plots the imposed chamber temperature $T_{\infty}(t)$ as a function of time featuring three successive heating/cooling cycles with temperature ramp rate of 20,5 , and $2^{\circ} \mathrm{C} / \mathrm{h}$. 
Figure 6 plots the centerpoint temperature $T_{c}(t)$ (a) experimentally measured and (b) numerically predicted as a function of time $t$ during cooling at a temperature ramp rate of $20^{\circ} \mathrm{C} / \mathrm{h}$ for cement paste specimens without and with MPCM32D with a volume fraction $\phi_{c+s}$ of $0.1,0.2$, or 0.3 . The temperatures within the PCM-mortar composite and the pure cement paste specimens were nearly identical until they diverged sharply at about $30^{\circ} \mathrm{C}$. This corresponded to the sharp onset of phase change during cooling illustrated in Figure 4b. Figure 6a features well-defined divergence and convergence points between the temperatures within cement paste and PCM-mortar composite specimens. This was observed in cooling curves for all ramp rates considered and for cylinders containing either MPCM24D or MPCM32D (see Supplementary material). As the microencapsulated PCM volume fraction $\phi_{c+s}$ increased, the temperature within the PCM-mortar specimens diverged more dramatically from that within the cement paste specimens during phase change. The PCM-mortar composite also took longer to cool down to the imposed chamber temperature. This can be attributed to the fact that the thermal energy stored within the specimen in the form of PCM latent heat during heating and released during cooling increased as $\phi_{c+s}$ increased. Figure $6 \mathrm{~b}$ indicates that the numerically predicted centerpoint temperature $T_{c}(t)$ during cooling at $20^{\circ} \mathrm{C} / \mathrm{h}$ agreed very well with experimental measurements and captured the above mentioned features. The numerical simulations used the measured specific heat $c_{p, c+s}(T)$ of the microencapsulated PCM shown in Figure 4b. The centerpoint temperature of the PCM-mortar composite specimens $T_{c, \text { comp }}(t)$ converged with that of the pure cement paste $T_{c, m}(t)$ during the isothermal hold at $T_{\infty}(t)=5^{\circ} \mathrm{C}$ around the same time experimentally and numerically.

Figure 6 also plots the centerpoint temperature $T_{c}(t)(\mathrm{c})$ experimentally measured and (d) numerically predicted as a function of time $t$ during heating at a temperature ramp rate of $20^{\circ} \mathrm{C} / \mathrm{h}$ for cement paste specimens without and with MPCM32D with a volume fraction $\phi_{c+s}$ of $0.1,0.2$, or 0.3 . The centerpoint temperature within PCM mortar specimens $T_{c, \text { comp }}(t)$ diverged gradually from that within cement paste $T_{c, m}(t)$ between 10 and $20^{\circ} \mathrm{C}$. This was consistent with the gradual onset of phase change during heating observed in Figure 
4b. Figure $6 \mathrm{~d}$ indicates that the numerically predicted centerpoint temperature $T_{c}(t)$ during heating at $20^{\circ} \mathrm{C} / \mathrm{h}$ also agreed very well with experimental measurements.

Finally, similar agreement was observed between experimental measurements and numerical predictions of $T_{c}(t)$ during cooling and heating at a temperature ramp rate of 5 and $2^{\circ} \mathrm{C} / \mathrm{h}$ and for cement paste containing MPCM24D (see Supplementary material). These results established experimentally the validity of the numerical simulation tool and of the expressions of the effective thermal properties numerically validated in previous studies $[5,11,12]$.

\subsubsection{Energy indicator}

The shaded area in Figure 6d illustrates the energy indicator EI associated with heating a PCM-mortar composite specimen containing microencapsulated PCM with volume fraction $\phi_{c+s}$ of 0.3 . The small area enclosed between 27 and 28 hours corresponds to the minor phase change peak in $c_{p, c+s}(T)$ shown in Figure $4 \mathrm{~b}$ around $5^{\circ} \mathrm{C}$. It was important to define $t_{i}$ and $t_{f}$ to include this area to avoid underestimating $E I$. It is evident that the surface area enclosed between $T_{c, c o m p}(t)$ and $T_{c}(t)$, i.e., the energy indicator, increased with increasing microencapsulated PCM volume fraction $\phi_{c+s}$. The energy indicator accounts for the cumulative effects of adding microencapsulated PCM to a cementitious mortar on its latent and sensible thermal energy storage and on its thermal resistance. Therefore, it should be larger when the temporal evolution within a PCM-mortar specimen is significantly delayed by larger latent or sensible heat storage and/or by smaller effective thermal conductivity compared with a PCM-free (i.e., plain cement-based) composite specimen.

Figure 7a shows the experimentally measured energy indicator $E I$ as a function of microencapsulated PCM volume fraction $\phi_{c+s}$ during heating and cooling at a temperature ramp rate of 20,5 , and $2^{\circ} \mathrm{C} / \mathrm{h}$ for PCM-mortar composite specimens containing MPCM24D. The experimental uncertainties were estimated based on three repeated experiments on specimens containing MPCM24D. The error bars shown correspond to a $95 \%$ confidence interval. Figure 7 a indicates that the energy indicator $E I$ increased nearly linearly with $\phi_{c+s}$ during heating and cooling at any temperature ramp rate. In addition, EI did not depend strongly 
on the temperature ramp rate. In fact, the linear fit was $E I=38 \phi_{c+s}$ with a coefficient of determination $\mathrm{R}^{2}$ larger than 0.99 for all conditions considered. Figure $7 \mathrm{~b}$ shows the numerical predictions of $E I$ as a function of $\phi_{c+s}$ corresponding to the experimental conditions of Figure 7a. The numerically predicted values of $E I$, averaged between heating and cooling for each ramp rate and fitted as $E I=47 \phi_{c+s}$, were $15-25 \%$ larger than the experimental measurements shown in Figure 7a.

Similarly, Figure 7c shows the experimentally measured energy indicator $E I$ as a function of $\phi_{c+s}$ during cooling and heating at a ramp rate of 20,5 , and $2^{\circ} \mathrm{C} / \mathrm{h}$ for PCM-mortar composite specimens containing MPCM32D. For this different PCM, the energy indicator $E I$ also increased nearly linearly with $\phi_{c+s}$ during heating and cooling at any ramp rate. The slope of the linear fit was steeper than that observed for MPCM24D. This can be attributed to the larger latent heat of fusion $h_{s f}$ of MPCM32D. Here also, EI did not depend strongly on the imposed chamber temperature ramp rate. The linear fit was such that $E I=49 \phi_{c+s}$ with $\mathrm{R}^{2}$ larger than 0.98 for all conditions considered. This suggests that EI may be evaluated at any ramp rate. Figure $7 \mathrm{~d}$ shows the numerical predictions of $E I$ as a function of $\phi_{c+s}$ corresponding to the conditions of Figure 7c. The numerically predicted values of $E I$, averaged between heating and cooling for each ramp rate and fitted as $E I=51 \phi_{c+s}$, were 2-6\% larger than those measured experimentally and shown in Figure $7 \mathrm{c}$.

The numerically predicted values of $E I$ fell very close to experimental measurements. However, they systematically exceeded experimental data by up to 25 and $6 \%$ for PCMmortar composite specimens containing MPCM24D or MPCM32D, respectively. Indeed, the numerical predictions shown in Figures $7 \mathrm{~b}$ and $7 \mathrm{~d}$ represent the ideal case in which the full latent heat storage capacity of the microencapsulated PCM may be utilized during melting or solidification. Experimentally, however, some microcapsules may burst during the synthesis process. In addition, we speculate that the enthalpy of phase change may decrease in caustic aqueous environments such as those encountered in cementitious pore solutions due to chemical interactions between the PCM and sulfate ions. These phenomena 
may explain the mismatch between the experimentally measured and numerically predicted values of $E I$.

The energy indicator EI was also predicted numerically using the microencapsulated PCM specific heat $c_{p, c+s}(T)$ measured experimentally at a temperature ramp rate of $10^{\circ} \mathrm{C} / \mathrm{min}$ (see Supplementary material). This led to a greater difference between $E I$ predicted during

heating and cooling. However, EI was on the same order of magnitude as that using $c_{p, c+s}(T)$ obtained at $1^{\circ} \mathrm{C} / \mathrm{min}$ (Figure 7 ). This can be attributed to the facts that (i) the measured PCM latent heat of fusion $h_{s f}$ did not strongly depend on the temperature ramp rate and (ii) EI captured the effect of latent heat over a complete melting or freezing period. Numerical predictions using $c_{p, c+s}(T)$ obtained at $10^{\circ} \mathrm{C} / \mathrm{min}$ also captured the linear dependence of $E I$ on $\phi_{c+s}$ and independence of $E I$ on heating and cooling ramp rate. In practice, this is useful since DSC measurements at $1^{\circ} \mathrm{C} / \mathrm{min}$ can be very time consuming while they are faster and routinely practiced at $10^{\circ} \mathrm{C} / \mathrm{min}$. Indeed, ASTM Standard E1269-11 specifies a heating and cooling ramp rate of $20^{\circ} \mathrm{C} / \mathrm{min}$ when measuring specific heat capacity by DSC [22].

\subsection{Parametric study}

The following section presents a parametric study using the simulation tool previously validated to assess the effects of (i) latent heat of fusion $h_{s f}$, (ii) specimen radius $r_{i}$, and (iii) PCM thermal conductivity $k_{c}$ on the energy indicator $E I$. Such a study would be very time consuming and costly if it were performed experimentally. In order to better parametrize the problem, the PCM specific heat was taken to be a step or a Gaussian function of temperature given by Equations (1) and (2), respectively. The simulated PCM-mortar composite specimen was exposed to the same temperature cycle $T_{\infty}(t)$ shown in Figure 5 . The plots of centerpoint temperature $T_{c}(t)$ during successive heating and cooling cycles showed the same qualitative behavior as the plots shown in Figures 6a through 6d.

The idealized PCM specific heat profiles simulated did not include hysteresis and thus the energy indicator was the same during heating and cooling and for any temperature ramp rate. Additionally, the energy indicator was found to be independent of the phase change 
temperature $T_{p c}$ and of the temperature window $\Delta T_{p c}$ as long as the imposed temperature cycle contained the entire phase change temperature window. Thus, in the following sections, $T_{p c}$ and $\Delta T_{p c}$ were arbitrarily taken to be 20 and $10^{\circ} \mathrm{C}$, respectively.

\subsubsection{Effect of latent heat of fusion}

Figure 8a plots the energy indicator EI predicted as a function of latent heat of fusion $h_{s f}$ ranging from 100 to $250 \mathrm{~kJ} / \mathrm{kg}$ for $\phi_{c+s}$ equal to $0.1,0.2$, and 0.3 for the baseline case with $r_{i}=38.1 \mathrm{~mm}$ and $k_{c}=0.21 \mathrm{~W} /(\mathrm{m} \cdot \mathrm{K})$. Figure 8a indicates that the energy indicator $E I$ increased linearly with $h_{s f}$ for any given value of $\phi_{c+s}$ considered. Additionally, EI increased more steeply with $h_{s f}$ for larger values of $\phi_{c+s}$.

Finally, the temporal evolution of the centerpoint temperature within specimens during phase change, and thus the value of $E I$, were nearly identical when imposing the PCM specific heat $c_{p, c}(T)$ as a step or as a Gaussian function of temperature (see Supplementary material). Thus, any PCM specific heat function may be used to predict EI numerically,

as long as (i) the area enclosed by the curve $c_{p, c}(T)$ and the line $c_{p, c}=c_{p, c, s}$ corresponds to $h_{s f}$ and (ii) the complete phase change temperature window is included in the range of temperature variation within the specimen. Henceforth, the PCM specific heat was imposed as a step function of temperature given by Equation (1).

\subsubsection{Effect of specimen radius}

Figure 8b plots the energy indicator EI predicted numerically as a function of the specimen radius $r_{i}$ up to $72 \mathrm{~mm}$ for microencapsulated PCM volume fraction $\phi_{c+s}$ equal to $0.1,0.2$, and 0.3. The latent heat of fusion $h_{s f}$ and thermal conductivity $k_{c}$ of the PCM were the same as in the baseline case (Table 1 ) and equal to $160 \mathrm{~kJ} / \mathrm{kg}$ and $0.21 \mathrm{~W} /(\mathrm{m} \cdot \mathrm{K})$, respectively. The length $L$ of the cylinder was also varied such that the aspect ratio $d_{i} / L$ was constant and equal to 0.5 . This ensured that $1 \mathrm{D}$ radial heat conduction prevailed at the center plane $z=L / 2$. The duration of the isothermal holds at the maximum and minimum temperatures was increased from 4 up to 14 hours with increasing specimen radius $r_{i}$ to ensure that 
the PCM-mortar composite specimen reached thermal equilibrium during the isothermal hold. Figure 8b indicates that the energy indicator increased quadratically with increasing specimen radius, i.e., $E I=a r_{i}+b r_{i}^{2}$ where the coefficients $a$ and $b$ depend on $\phi_{c+s}, h_{s f}$, and on the thermal properties $\left(\rho, c_{p}\right.$, and $\left.k\right)$ of the core, shell, matrix, and mold materials. As the specimen radius and thus the mass of microencapsulated PCM increased, more thermal energy was stored or released in the form of latent heat during heating or cooling, respectively.

\subsubsection{Effect of PCM thermal conductivity}

Figure 8c plots the energy indicator $E I$ as a function of PCM thermal conductivity $k_{c}$ ranging from 0.01 to $10 \mathrm{~W} /(\mathrm{m} \cdot \mathrm{K})$ for $\phi_{c+s}$ of $0.1,0.2$, and $0.3, h_{s f}=160 \mathrm{~kJ} / \mathrm{kg}$, and $r_{i}=38.1 \mathrm{~mm}$. It shows that EI decreased sharply with increasing $k_{c}$ between about 0.1 and $10 \mathrm{~W} /(\mathrm{m} \cdot \mathrm{K})$. Note that this range of $k_{c}$ encompasses most commercially available PCMs [30]. In fact, most commercially available organic PCMs have thermal conductivities between 0.1 and 0.3 $\mathrm{W} /(\mathrm{m} \cdot \mathrm{K})$, while inorganic and eutectic PCMs can have thermal conductivities reaching as high as $1 \mathrm{~W} /(\mathrm{m} \cdot \mathrm{K})$ [30]. Within this range, $E I$ was increasingly sensitive to $k_{c}$ as $\phi_{c+s}$ increased. In all cases, it reached a plateau for low PCM thermal conductivity and tended toward zero for $k_{c}$ exceeding $10 \mathrm{~W} /(\mathrm{m} \cdot \mathrm{K})$. Interestingly, the upper limit for small values of $k_{c}$ increased substantially with increasing $\phi_{c+s}$, while the lower limit for large $k_{c}$ did not depend strongly on $\phi_{c+s}$. For energy efficient building envelopes, augmentation of the thermal resistance provided by the PCM-mortar composite is desired and thus PCMs with small thermal conductivity $k_{c}$ are preferred.

\subsection{Correlation to performance metrics}

\subsubsection{Energy flux reduction}

This section utilizes a numerical model presented in a recent study [5] to simulate 1D transient heat transfer through a $10 \mathrm{~cm}$ thick microencapsulated PCM-concrete composite wall. The inner wall surface was subjected to a constant indoor temperature $T_{i n}=20^{\circ} \mathrm{C}$ while the outer wall surface was subjected to sinusoidal outdoor temperature oscillations between $T_{\min }$ 
and $T_{\max }$ and to sinusoidal solar radiation flux. The convective heat transfer coefficients at the inner and outer wall surfaces were taken to be 8 and $20 \mathrm{~W} /\left(\mathrm{m}^{2} \cdot \mathrm{K}\right)$, respectively [5]. The PCM specific heat was taken to be a step function of temperature given by Equation (1) where $T_{p c}$ was equal to the indoor temperature $T_{i n}$ and $\Delta T_{p c}=3{ }^{\circ} \mathrm{C}$. We defined the diurnal energy flux reduction $E_{r}$ as the relative difference between the daily energy fluxes (in $\mathrm{J} / \mathrm{m}^{2}$ ) through a plain concrete wall and through a microencapsulated PCM-concrete composite wall [5]. The diurnal energy flux reduction $E_{r}$ (i) increased linearly with both the PCM volume fraction and the latent heat of fusion and their product (not shown) and (ii) was independent of the phase change temperature window as long as it did not extend beyond the range of wall temperatures variation [5].

Table 2 summarizes six cases considered featuring microencapsulated PCM volume fraction $\phi_{c+s}$ ranging from 0 to 0.3 , latent heat of fusion $h_{s f}$ ranging from 100 to $200 \mathrm{~kJ} / \mathrm{kg}$, and PCM thermal conductivity $k_{c}$ ranging from 0.21 to $2 \mathrm{~W} /(\mathrm{m} \cdot \mathrm{K})$. In Cases $1-5, T_{\min }$ and $T_{\max }$ were chosen as 0 and $40^{\circ} \mathrm{C}$, respectively, such that the diurnal variation of the inner wall surface temperature included the entire phase change temperature window. On the other hand, Case 6 features more realistic conditions with outdoor temperature varying between 10 and $30^{\circ} \mathrm{C}$. Figure 9 plots the diurnal energy flux reduction $E_{r}$ through the composite wall estimated for the six different cases of Table 2 as a function of energy indicator $E I$ for a cylinder of radius $r_{i}=38.1 \mathrm{~mm}$ and of the same composition as the wall. The energy flux reduction $E_{r}$ for Cases 1-5 collapsed on the same curve and was linearly proportional to the energy indicator $E I$, i.e., $E_{r}=3.73 E I$. For Case $6, E_{r}$ was larger than previous cases but nonetheless increased with increasing $\phi_{c+s}$ before saturating. This can be attributed to the fact that the PCM did not experience complete melting and freezing. Figure 9 establishes the direct correlation between the energy savings achieved by a wall and the energy indicator for a small cylindrical specimen of the same material. Thus, EI can be used to compare the potential of microencapsulated PCM-mortar composite specimens of differing compositions to reduce the energy flux through building walls. This is particularly useful in cases where the experimentalist lacks precise knowledge of the constituent material properties and vol- 
ume fractions or experience with numerical modelling techniques. Moreover, in contrast to the energy flux reduction, the energy indicator does not require heat flux measurements but instead relies on simple temperature measurements.

\subsubsection{Peak temperature reached during early hydration}

Cylindrical PCM-mortar composite specimens were prepared using the method presented in Section 3.1 with different volume fractions $\phi_{c+s}$. They were cast in PVC molds of inner radius $38.1 \mathrm{~mm}$ and immediately placed in the freeze-thaw chamber and subjected to a constant air temperature $T_{\infty}(t)$ of $26^{\circ} \mathrm{C}$.

Figure 10a plots the temporal evolution of the centerpoint temperature $T_{c}(t)$ within cement paste specimens without and with MPCM24D with volume fraction $\phi_{c+s}$ of $0.1,0.2$, or 0.3 during the cement hydration period. It shows that, for all specimens, the centerpoint temperature $T_{c}(t)$ increased to a peak temperature $T_{p}$ during hydration before decreasing to the imposed chamber temperature of $26^{\circ} \mathrm{C}$. This temperature rise was due to thermal energy generated by the exothermic hydration reaction occurring upon mixing cement and water. Figure 10a shows that the peak hydration temperature $T_{p}$ decreased and was delayed with increasing microencapsulated PCM volume fraction $\phi_{c+s}$.

Figure 10b plots the peak hydration temperature $T_{p}$ in PCM-mortar composite specimens with $\phi_{c+s}$ ranging from 0 to 0.3 as a function of energy indicator $E I$ previously measured for identical specimen compositions. The energy indicator was obtained by averaging measurements for cooling rates of 20,5 , and $2^{\circ} \mathrm{C} / \mathrm{h}$. The peak hydration temperature was obtained by averaging measurements of three specimens. The error bars shown for $E I$ and $T_{p}$ correspond to $95 \%$ and $63 \%$ confidence intervals, respectively. Figure $10 \mathrm{~b}$ indicates that the peak hydration temperature $T_{p}$ decreased nearly linearly with increasing energy indicator $E I$ such that $T_{p}=40.1-0.45 E I$ with $\mathrm{R}^{2} \approx 0.96$. Note that the peak hydration temperature $T_{p}$ observed here was smaller than that which would be expected in realistic concrete sections. This is attributable, in part, to the very slight insulating effect offered by the $2 \mathrm{~mm}$ mold wall. If the quantity of insulation were increased, e.g., to better capture semi-adiabatic 
temperature as occurs in realistic concrete sections, we would expect to observe higher peak hydration temperature $T_{p}$. This is significant, as reducing the peak hydration temperature $T_{p}$ has been suggested as a method of reducing the risk of early-age cracking in cementitious elements $[31,32]$. These results establish that $E I$ is a relevant figure of merit to compare the potential of microencapsulated PCM-mortar composites of different compositions to mitigate this risk.

\section{Conclusion}

An energy indicator was introduced as a novel figure of merit to quantify the thermal performance of cementitious microencapsulated PCM composite materials. It can be evaluated based on a single heating, hold, and cooling test encompassing the PCM phase change temperature window at any ramp rate. Numerical predictions of the centerpoint temperature within cylindrical PCM-mortar composite specimens and the associated predictions of the energy indicator agreed very well with experimental measurements. The energy indicator was found to (i) increase linearly with increasing microencapsulated PCM volume fraction $\phi_{c+s}$ and latent heat of fusion $h_{s f}$, (ii) increase quadratically with the specimen radius $r_{i}$, and (iii) decrease with increasing PCM thermal conductivity $k_{c}$. The energy indicator measured for small cylindrical specimens was shown to correlate with the diurnal energy flux reduction achieved by adding microencapsulated PCM to a concrete wall. Similarly, the peak hydration temperature reached within cementitious materials decreased nearly linearly with increasing energy indicator. Thus, the energy indicator EI can be used as a figure of merit to rapidly evaluate and select PCM-mortar composites for energy efficient buildings and crack-resistant concrete.

\section{Acknowledgements}

This manuscript was prepared as a result of work sponsored by the California Energy Commission (Contract: PIR:-12-032), the National Science Foundation (CMMI: 1130028) and the University of California, Los Angeles (UCLA). It does not necessarily represent the views 
of the Energy Commission, its employees, the State of California, or the National Science Foundation. The Energy Commission, the State of California, its employees, contractors, and subcontractors make no warranty, express or implied, and assume no legal liability for the information in this document; nor does any party represent that the use of this information will not infringe upon privately owned rights. This manuscript has not been approved or disapproved by the California Energy Commission nor has the California Energy Commission passed upon the accuracy or adequacy of the information in this paper. GNS would like to acknowledge discretionary support for this research provided by the Edward K. and Linda L. Rice Endowed Chair in Materials Science. 


\section{References}

[1] C. Castellón, A. Castell, M. Medrano, I. Martorell, and L.F. Cabeza, "Experimental study of PCM inclusion in different building envelopes", Journal of Solar Energy Engineering, vol. 131, no. 4, pp. 41006, 2009.

[2] Z. Zhang, G. Shi, S. Wang, X.g. Fang, and X. Liu, "Thermal energy storage cement mortar containing n-octadecane/expanded graphite composite phase change material", Renewable Energy, vol. 50, pp. 670-675, 2013.

[3] T.-C. Ling and C.-S. Poon, "Use of phase change materials for thermal energy storage in concrete: an overview", Construction and Building Materials, vol. 46, pp. 55 - 62, 2013.

[4] D. Snoeck, B. Priem, P. Dubruel, and N. De Belie, "Encapsulated phase-change materials as additives in cementitious materials to promote thermal comfort in concrete constructions", Materials and Structures, pp. 1-15, 2014.

[5] A.M. Thiele, G. Sant, and L. Pilon, "Diurnal thermal analysis of microencapsulated PCM-concrete composite walls", Energy Conversion and Management, vol. 93, pp. $215-227,2015$.

[6] A. Sharma, V.V. Tyagi, C.R. Chen, and D. Buddhi, "Review on thermal energy storage with phase change materials and applications", Renewable and Sustainable Energy Reviews, vol. 13, no. 2, pp. 318 - 345, 2009.

[7] M.F. Demirbas, "Thermal energy storage and phase change materials: an overview", Energy Sources, Part B: Economics, Planning, and Policy, vol. 1, no. 1, pp. 85-95, 2006.

[8] F. Fernandes, S. Manari, M. Aguayo, K. Santos, T. Oey, Z. Wei, G. Falzone, N. Neithalath, and G. Sant, "On the feasibility of using phase change materials (PCMs) to 
mitigate thermal cracking in cementitious materials", Cement and Concrete Composites, vol. 51, pp. $14-26,2014$.

[9] G. Evola, L. Marletta, and F. Sicurella, "A methodology for investigating the effectiveness of PCM wallboards for summer thermal comfort in buildings", Building and Environment, vol. 59, pp. 517-527, 2013.

[10] A. Castell and M.M. Farid, "Experimental validation of a methodology to assess PCM effectiveness in cooling building envelopes passively", Energy and Buildings, vol. 81, pp. $59-71,2014$.

[11] A.M. Thiele, A. Kumar, G. Sant, and L. Pilon, "Effective thermal conductivity of three-component composites containing spherical capsules", International Journal of Heat and Mass Transfer, vol. 73, pp. 177-185, 2014.

[12] J.D. Felske, "Effective thermal conductivity of composite spheres in a continuous medium with contact resistance", International Journal of Heat and Mass Transfer, vol. 47, no. 14, pp. 3453-3461, 2004.

[13] S.N. AL-Saadi and Z.J. Zhai, "Modeling phase change materials embedded in building enclosure: A review", Renewable and Sustainable Energy Reviews, vol. 21, pp. 659-673, 2013.

[14] P. Lamberg, R. Lehtiniemi, and A.-M. Henell, "Numerical and experimental investigation of melting and freezing processes in phase change material storage", International Journal of Thermal Sciences, vol. 43, no. 3, pp. 277-287, 2004.

[15] A.S. Kalagasidis, "A multi-level modelling and evaluation of thermal performance of phase-change materials in buildings", Journal of Building Performance Simulation, vol. 7, no. 4, pp. 289-308, 2014. 
[16] N. Ukrainczyk, S. Kurajica, and J. Šipušić, "Thermophysical comparison of five commercial paraffin waxes as latent heat storage materials", Chemical and Biochemical Engineering Quarterly, vol. 24, no. 2, pp. 129-137, 2010.

[17] ASTM Standard, "C305", Standard practice for mechanical mixing of hydraulic cement pastes and mortars of plastic consistency. ASTM International, West Conshohocken, PA, USA, 2014.

[18] K.-H. Kim, S.-E. Jeon, J.-K. Kim, and S. Yang, "An experimental study on thermal conductivity of concrete", Cement and Concrete Research, vol. 33, no. 3, pp. 363-371, 2003.

[19] J.A. Riddick, W.B. Bunger, and T.K. Sakano, Organic solvents: physical properties and methods of purification, John Wiley and Sons, New York, NY, $4^{\text {th }}$ edition, 1986.

[20] G. Gao, S. Moya, H. Lichtenfeld, A. Casoli, H. Fiedler, E. Donath, and H. Mohwald, "The decomposition process of melamine formaldehyde cores: the key step in the fabrication of ultrathin polyelectrolyte multilayer capsules", Macromolecular Materials and Engineering, vol. 286, no. 6, pp. 355-361, 2001.

[21] ASTM Standard, "C138", Standard test method for density (unit weight), yield, and air content (gravimetric) of concrete. ASTM International, West Conshohocken, PA, USA, 2010.

[22] ASTM Standard, "E1269-11", Standard test method for determining specific heat capacity by differential scanning calorimetry. ASTM International, West Conshohocken, PA, USA, 2011.

[23] K.L. Ramakumar, M.K. Saxena, and S.B. Deb, "Experimental evaluation of procedures for heat capacity measurement by differential scanning calorimetry", Journal of Thermal Analysis and Calorimetry, vol. 66, no. 2, pp. 387-397, 2001. 
[24] T.L. Bergman, A.S. Lavine, F.P. Incropera, and D.P. DeWitt, Fundamentals of Heat and Mass Transfer, John Wiley \& Sons, New York City, NY, $7^{\text {th }}$ edition, 2011.

[25] "MPCM Technical Information", Tech. Rep., Microtek Laboratories Inc., Dayton, OH.

[26] R.K. Rajput, Engineering Materials $\& 3$ Metallurgy, S. Chand Limited, New Delhi, India, $1^{\text {st }}$ edition, 2006.

[27] D.P. Bentz, "Transient plane source measurements of the thermal properties of hydrating cement pastes", Materials and Structures, vol. 40, no. 10, pp. 1073-1080, 2007.

[28] M. Delgado, A. Lázaro, J. Mazo, and B. Zalba, "Review on phase change material emulsions and microencapsulated phase change material slurries: materials, heat transfer studies and applications", Renewable and Sustainable Energy Reviews, vol. 16, no. 1, pp. 253-273, 2012.

[29] G. Albright, M. Farid, and S. Al-Hallaj, "Development of a model for compensating the influence of temperature gradients within the sample on DSC-results on phase change materials", Journal of Thermal Analysis and Calorimetry, vol. 101, no. 3, pp. 1155$1160,2010$.

[30] B. Young, A.M. Thiele, A. Fujii, G. Sant, and L. Pilon, "Thermophysical properties of phase change materials", 2013, www.seas.ucla.edu/ pilon/downloads.htm.

[31] H. Mihashi and J.P.B. de Leite, "State-of-the-art report on control of cracking in early age concrete", Journal of Advanced Concrete Technology, vol. 2, no. 2, pp. 141-154, 2004.

[32] D.P. Bentz and W.J. Weiss, "REACT: reducing early-age cracking today", Concrete Plant International, vol. 3, pp. 56-61, 2008.

[33] "Rigid polyvinyl chloride material data sheet", Tech. Rep. AV0780 EN, Rehau, Muri, Switzerland, 2013. 


\section{List of Tables}

1 Density $\rho$, specific heat capacity $c_{p}$, and thermal conductivity $k$ of PCM, melamine-formaldehyde (MF), cement paste, and PVC. . . . . . . . . . 36

2 Microencapsulated PCM volume fraction $\phi_{c+s}$, latent heat of fusion $h_{s f}$ and thermal conductivity $k_{c}$ of PCM, and minimum $T_{\min }$ and maximum $T_{\max }$ outdoor temperatures corresponding to cases 1-6 in Figure 9 . . . . . . . . 37

\section{List of Figures}

1 Schematic illustration of the dimensions of a PVC cylinder containing a $76.2 \mathrm{x}$ 152.4 mm microencapsulated PCM-mortar composite specimen and detailing the locations of thermocouples and with the coordinate system. All units are

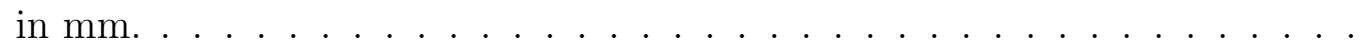

2 Schematic of the numerically simulated two-dimensional heat transfer in a quarter of the cylindrical PVC container of microencapsulated PCM-mortar composite along with the coordinate system, the associated boundary conditions, and the mesh elements used in numerical simulation. . . . . . . . . .

3 Measured particle size distribution of solid constituents of microencapsulated PCM-cement paste composites. . . . . . . . . . . . . . . . .

4 Specific heat of microencapsulated PCM (a) MPCM24D and (b) MPCM32D (Microtek Laboratories Inc.) as a function of temperature measured by DSC with a temperature ramp rate of $1^{\circ} \mathrm{C} /$ min. . . . . . . . . . .

5 Centerpoint temperature $T_{c}(t)$ as a function of time within cement paste specimens without and with microencapsulated PCM volume fraction $\phi_{c+s}$ of 0.1 , 0.2 , or 0.3 subjected to an imposed chamber temperature $T_{\infty}(t)$ varying at a ramp rate of 20,5 , and $2^{\circ} \mathrm{C} / \mathrm{h} . \ldots \ldots \ldots \ldots$ 
6 Centerpoint temperature $T_{c}(t)$ as a function of time within cement paste specimens without and with MPCM32D with volume fraction $\phi_{c+s}$ of $0.1,0.2$, or 0.3 subjected to an imposed chamber temperature $T_{\infty}(t)$ during cooling at temperature ramp rate of $20^{\circ} \mathrm{C} / \mathrm{h}$ (a) measured experimentally and (b) predicted numerically and also during heating at temperature ramp rate of $20^{\circ} \mathrm{C} / \mathrm{h}$ (c) measured experimentally and $(\mathrm{d})$ predicted numerically. . . . . . . . . . .

7 Energy indicator $E I$ as a function of microencapsulated PCM volume fraction $\phi_{c+s}$ ranging from 0.1 to 0.3 for microencapsulated PCM-mortar specimens subjected to heating and cooling at a temperature ramp rate of 20,5 , and $2^{\circ} \mathrm{C} / \mathrm{h}$ for (a) experimental measurements and (b) numerical predictions for MPCM24D and (c) experimental measurements and (d) numerical predictions for MPCM32D. The linear fits feature $\mathrm{R}^{2}$ larger than 0.98 . . . . . . . . .

8 Energy indicator $E I$ as a function of (a) latent heat of fusion $h_{s f}$ ranging from 100 to $250 \mathrm{~kJ} / \mathrm{kg}$, (b) specimen radius $r_{i}$ up to $72 \mathrm{~mm}$, and (c) PCM thermal conductivity $k_{c}$ ranging from 0.01 to $10 \mathrm{~W} /\left(\mathrm{m}^{2} \cdot \mathrm{K}\right)$. Microencapsulated PCM volume fraction $\phi_{c+s}$ was taken as either $0.1,0.2$, or $0.3 \ldots \ldots . . . .$. 45

9 Correlation between the diurnal energy flux reduction $E_{r}$ achieved by a 10 cm thick PCM-mortar composite wall and the energy indicator EI of a small specimen of the same material predicted numerically. The parameters corresponding to Cases 1-6 are summarized in Table 2. The microencapsulated PCM volume fraction $\phi_{c+s}$ ranged from 0.05 to 0.3 , the latent heat of fusion $h_{s f}$ from 100 to $200 \mathrm{~kJ} / \mathrm{kg}$, and the PCM thermal conductivity $k_{c}$ from 0.21 to $2 \mathrm{~W} /(\mathrm{m} \cdot \mathrm{K})$. The linear fit features $\mathrm{R}^{2}$ larger than 0.99 . . . . . . . . .

10 (a) Experimentally measured centerpoint temperature $T_{c}(t)$ as a function of time within cement paste specimens without and with MPCM24D at volume fraction $\phi_{c+s}$ of $0.1,0.2$, or 0.3 during the cement hydration period. (b) Peak centerpoint temperature $T_{p}$ reached during cement hydration as a function of the corresponding energy indicator $E I \ldots \ldots \ldots \ldots$ 
Table 1: Density $\rho$, specific heat capacity $c_{p}$, and thermal conductivity $k$ of PCM, melamineformaldehyde (MF), cement paste, and PVC.

\begin{tabular}{lccccc}
\hline Material & Subscript & $\begin{array}{c}\rho \\
\left(\mathbf{k g} / \mathbf{m}^{3}\right)\end{array}$ & $\left.\begin{array}{c}c_{p} \\
(\mathbf{J} /(\mathbf{k g} \cdot \mathbf{K}))\end{array}\right)(\mathbf{W} /(\mathbf{m} \cdot \mathbf{K}))$ & $\mathbf{R e f .}$ \\
\hline PCM & $\mathbf{c}$ & 900 & 1900 & 0.21 & {$[16,25]$} \\
MF & $\mathbf{S}$ & 1500 & 1670 & 0.42 & {$[26]$} \\
Cement paste & $\mathbf{m}$ & 1965 & 1530 & 1 & {$[27]$} \\
PVC & PVC & 1420 & 1000 & 0.16 & {$[33]$} \\
\hline
\end{tabular}


Table 2: Microencapsulated PCM volume fraction $\phi_{c+s}$, latent heat of fusion $h_{s f}$ and thermal conductivity $k_{c}$ of PCM, and minimum $T_{\min }$ and maximum $T_{\max }$ outdoor temperatures corresponding to cases 1-6 in Figure 9.

\begin{tabular}{cccccc}
\hline & $\phi_{c+s}$ & $\begin{array}{c}h_{s f} \\
(\mathbf{k J} / \mathbf{k g})\end{array}$ & $\begin{array}{c}k_{c} \\
(\mathbf{W} /(\mathbf{m} \cdot \mathbf{K}))\end{array}$ & $\begin{array}{c}T_{\min } \\
\left({ }^{\circ} \mathbf{C}\right)\end{array}$ & $\begin{array}{c}T_{\max } \\
\left({ }^{\circ} \mathbf{C}\right)\end{array}$ \\
\hline $\mathbf{1}$ & 0.1 & $100-200$ & 0.21 & 0 & 40 \\
$\mathbf{2}$ & 0.2 & $100-200$ & 0.21 & 0 & 40 \\
$\mathbf{3}$ & 0.3 & $100-200$ & 0.21 & 0 & 40 \\
$\mathbf{4}$ & 0.15 & 180 & $0.21-2$ & 0 & 40 \\
$\mathbf{5}$ & 0.25 & 180 & $0.21-2$ & 0 & 40 \\
$\mathbf{6}$ & $0.05-0.3$ & 180 & 0.21 & 10 & 30 \\
\hline
\end{tabular}




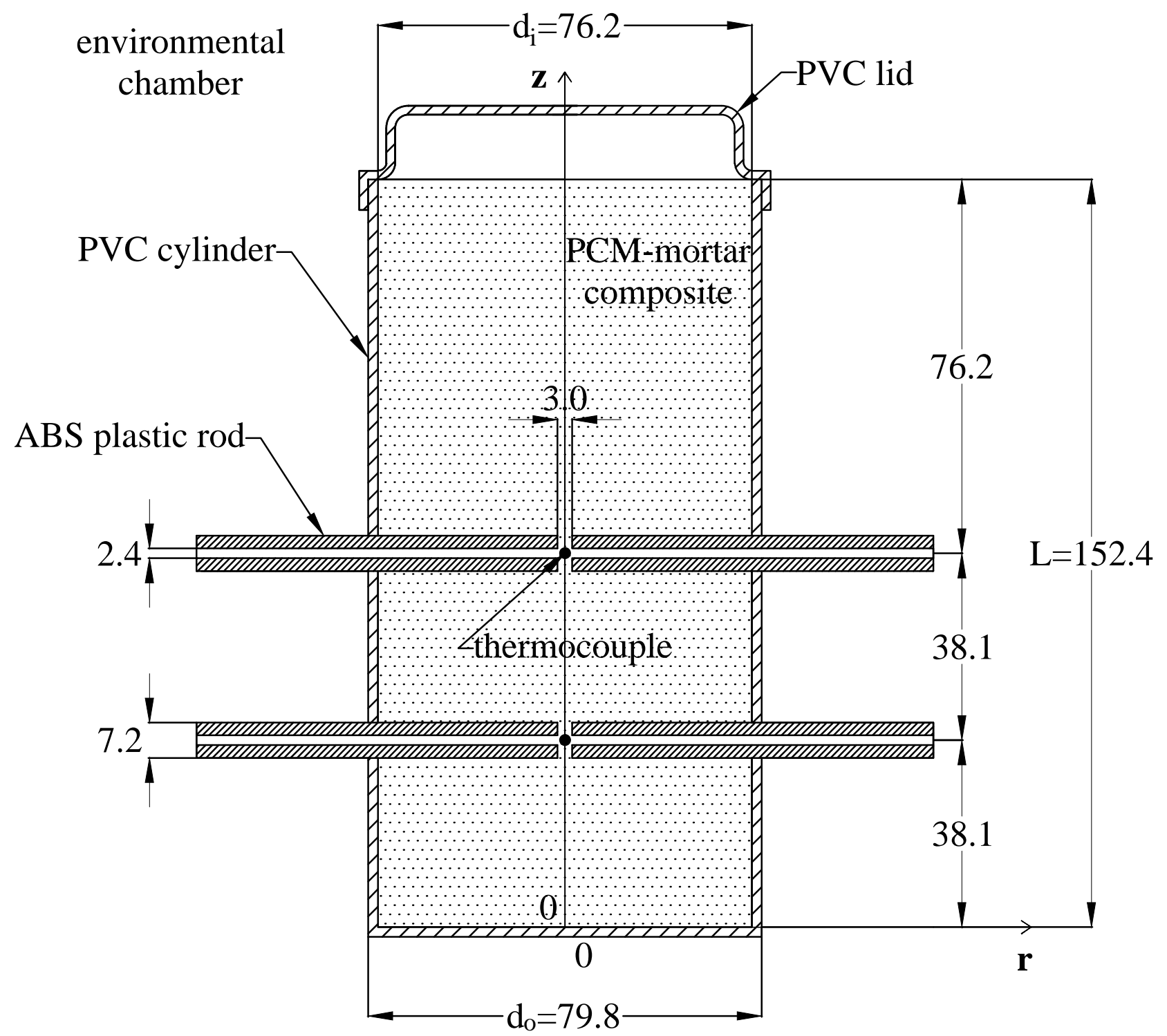

Figure 1: Schematic illustration of the dimensions of a PVC cylinder containing a $76.2 \mathrm{x}$ $152.4 \mathrm{~mm}$ microencapsulated PCM-mortar composite specimen and detailing the locations of thermocouples and with the coordinate system. All units are in $\mathrm{mm}$. 


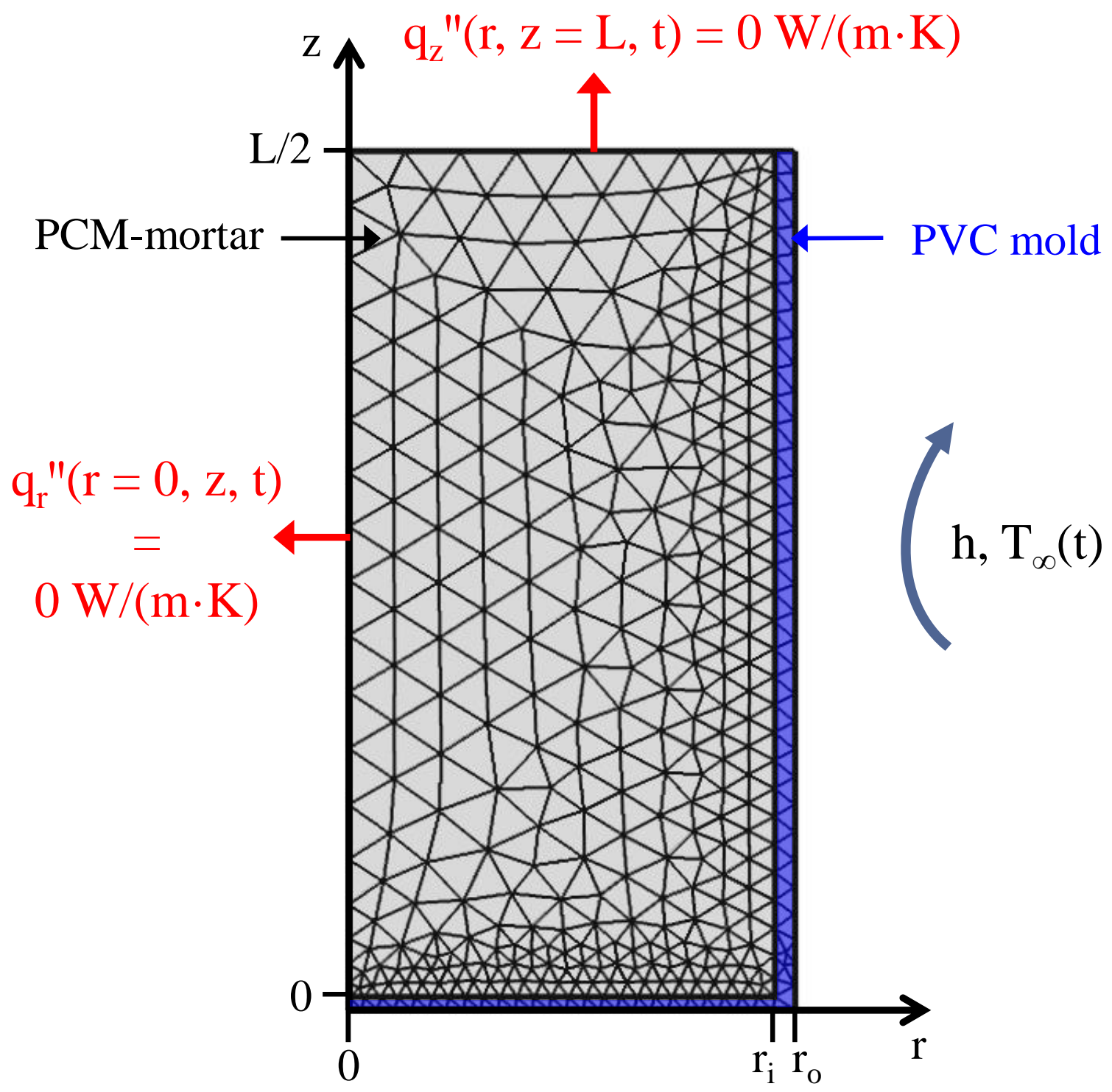

Figure 2: Schematic of the numerically simulated two-dimensional heat transfer in a quarter of the cylindrical PVC container of microencapsulated PCM-mortar composite along with the coordinate system, the associated boundary conditions, and the mesh elements used in numerical simulation. 


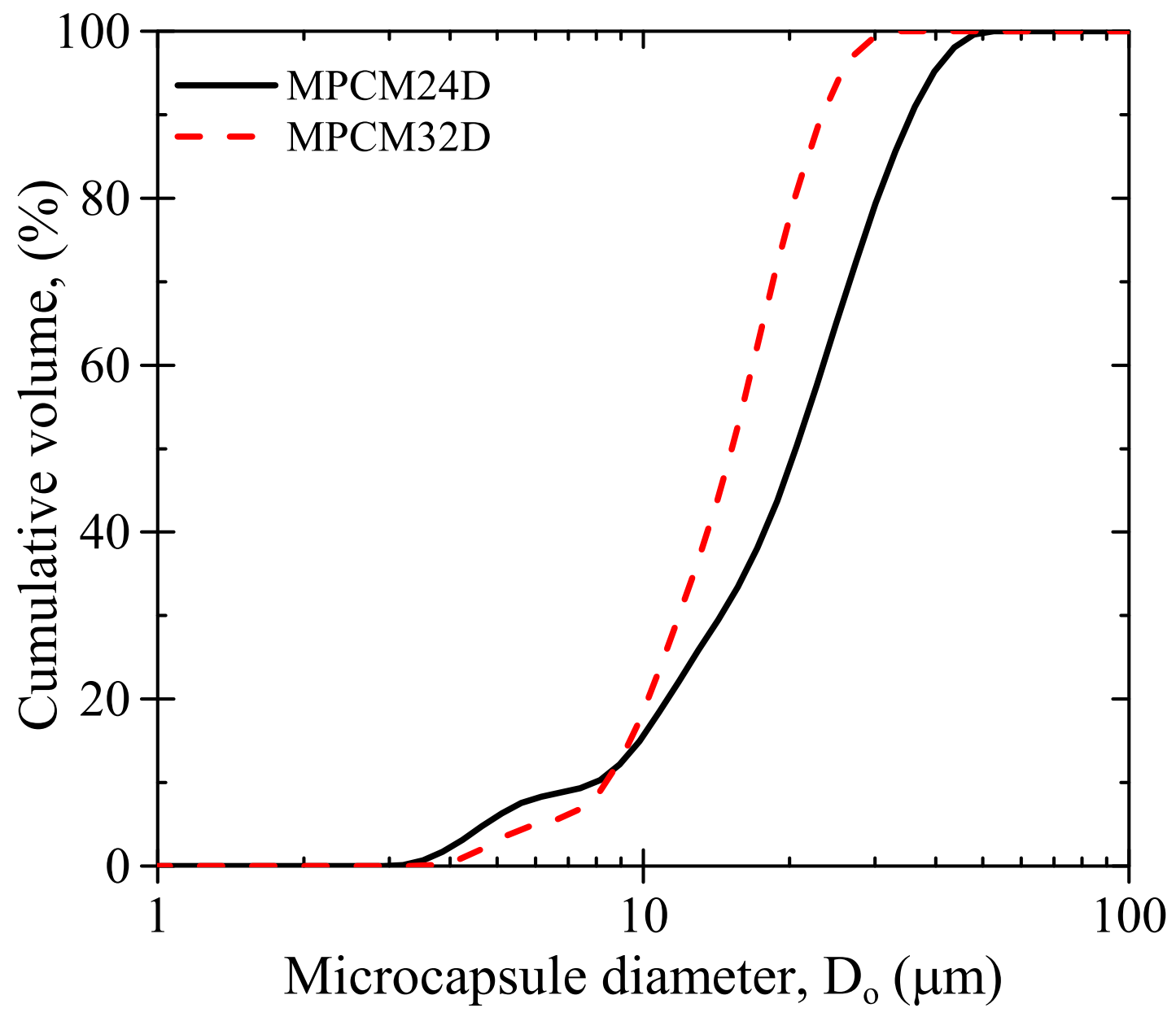

Figure 3: Measured particle size distribution of solid constituents of microencapsulated PCM-cement paste composites. 
(a)

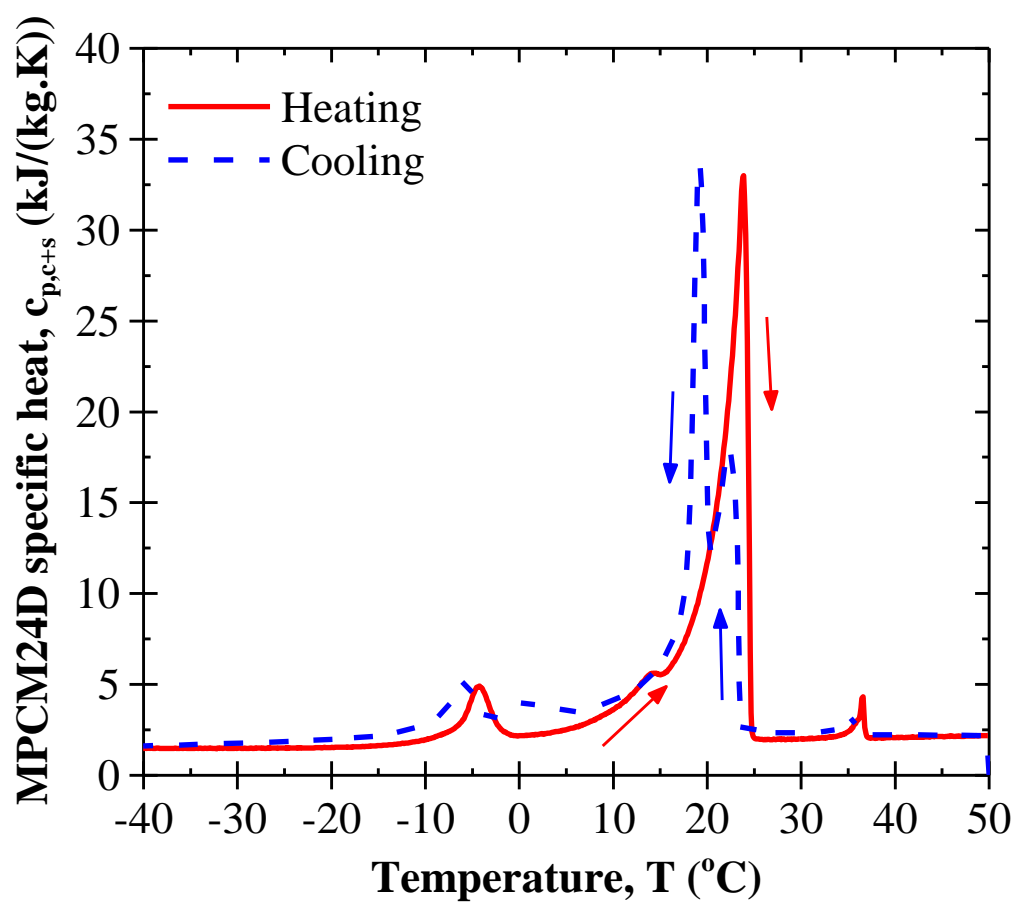

(b)

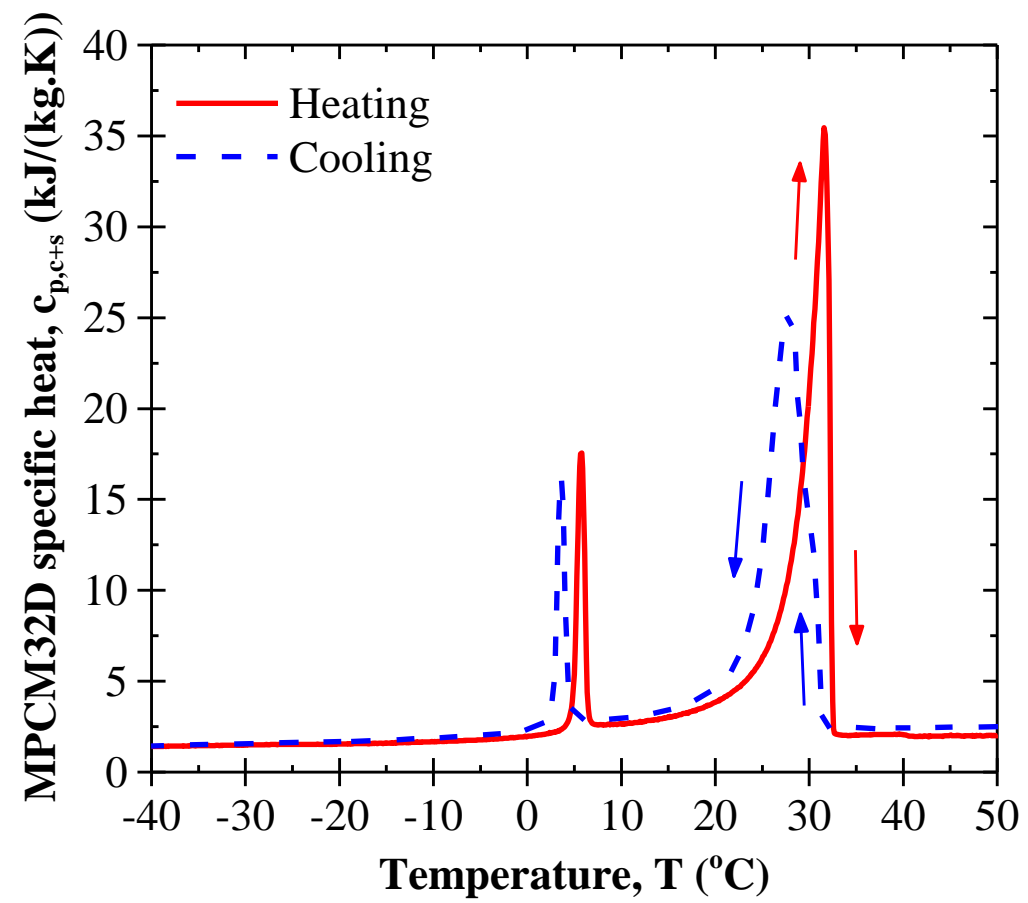

Figure 4: Specific heat of microencapsulated PCM (a) MPCM24D and (b) MPCM32D (Microtek Laboratories Inc.) as a function of temperature measured by DSC with a temperature ramp rate of $1^{\circ} \mathrm{C} / \mathrm{min}$. 


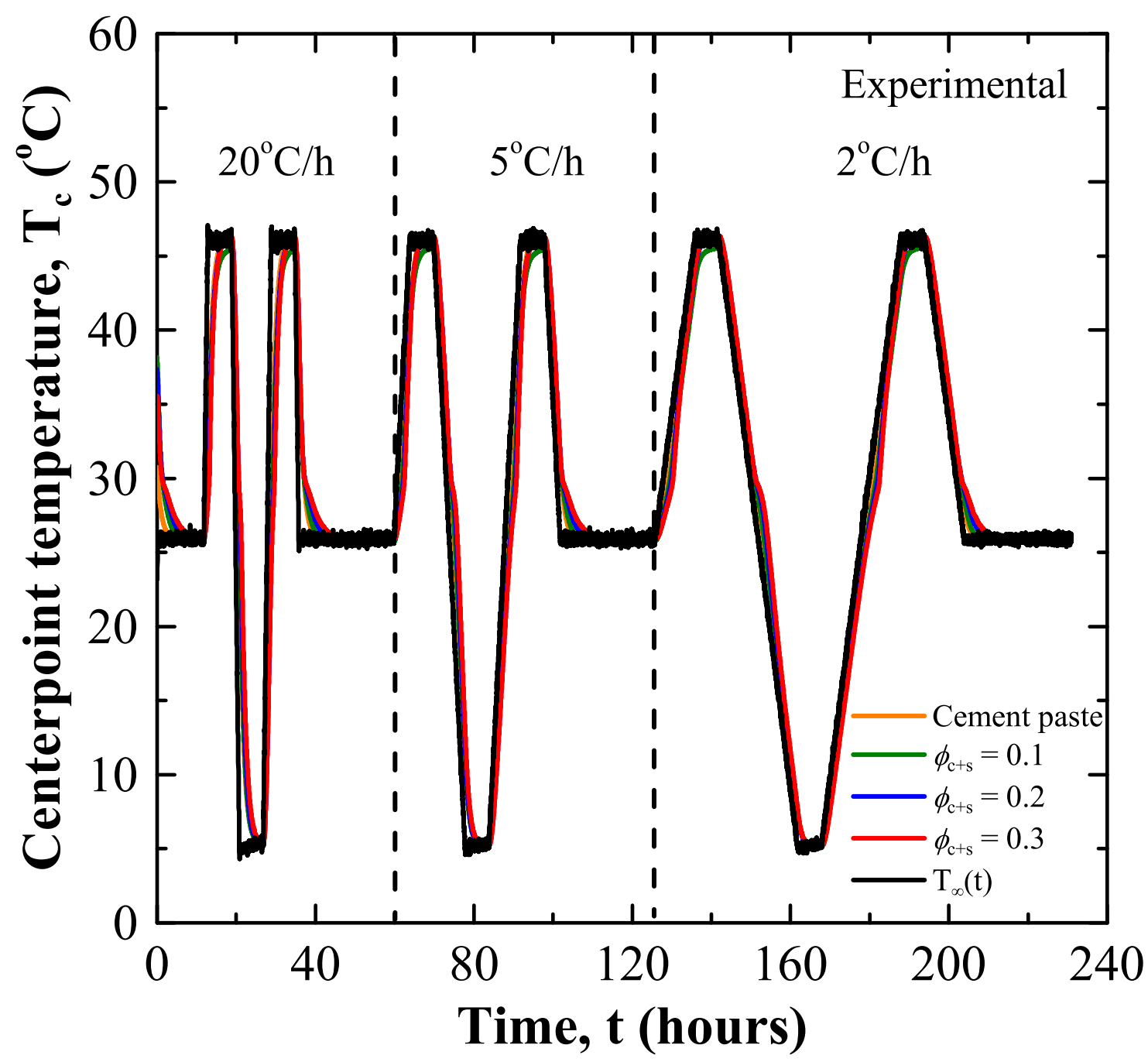

Figure 5: Centerpoint temperature $T_{c}(t)$ as a function of time within cement paste specimens without and with microencapsulated PCM volume fraction $\phi_{c+s}$ of $0.1,0.2$, or 0.3 subjected to an imposed chamber temperature $T_{\infty}(t)$ varying at a ramp rate of 20,5 , and $2^{\circ} \mathrm{C} / \mathrm{h}$. 
(a)

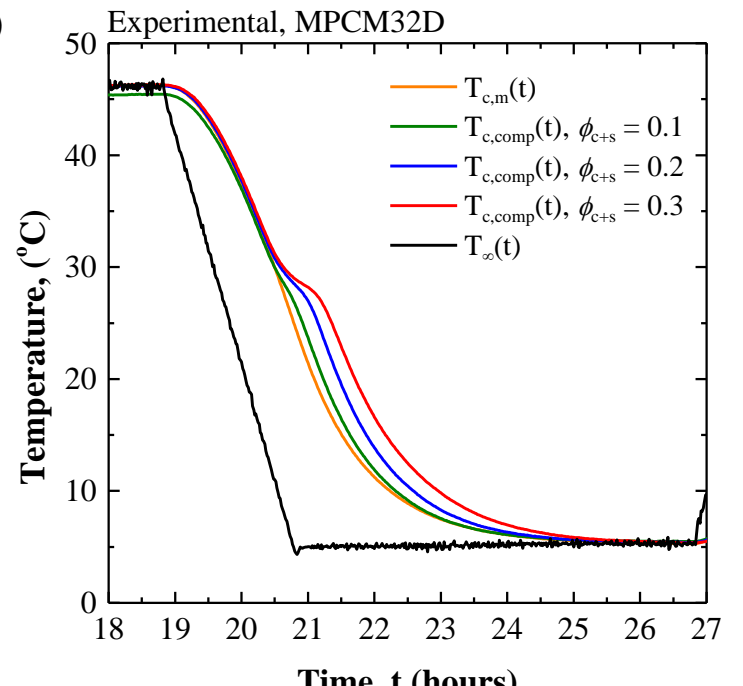

(c)

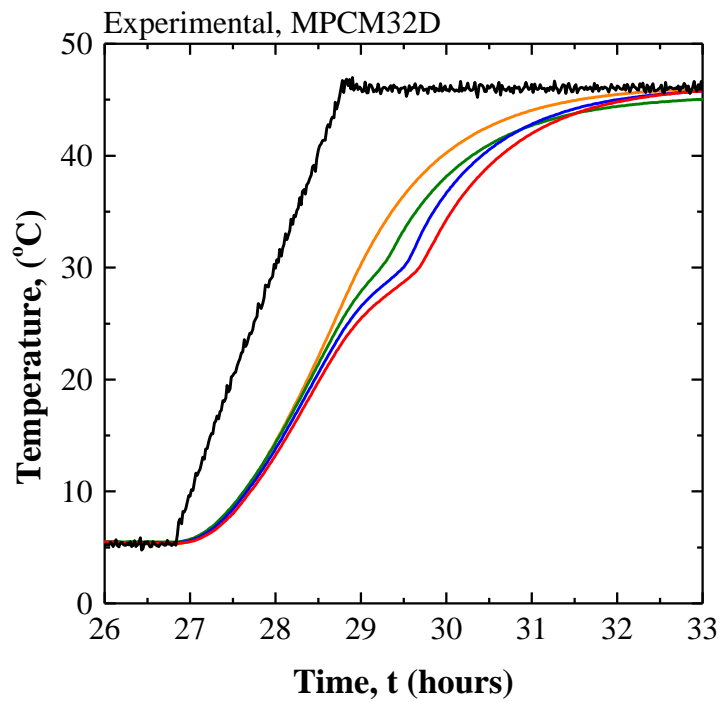

(b)

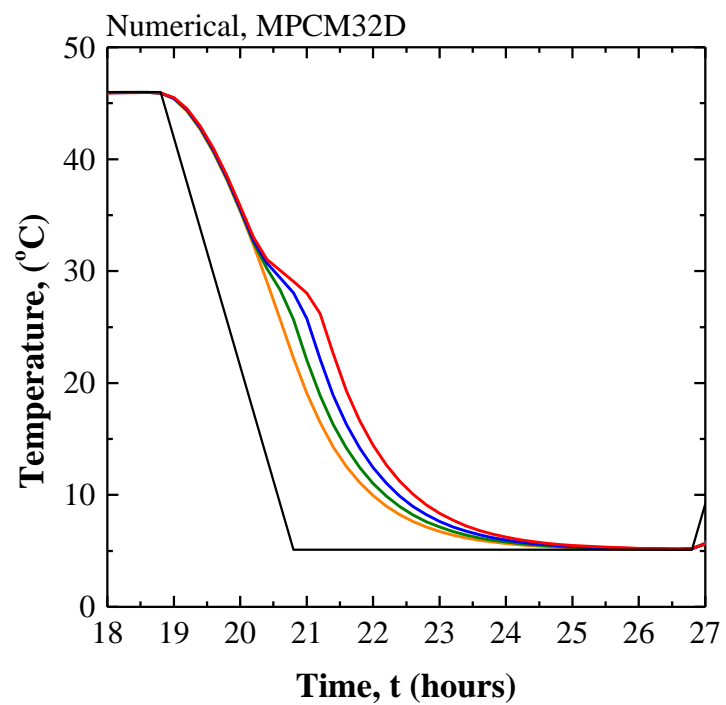

(d)

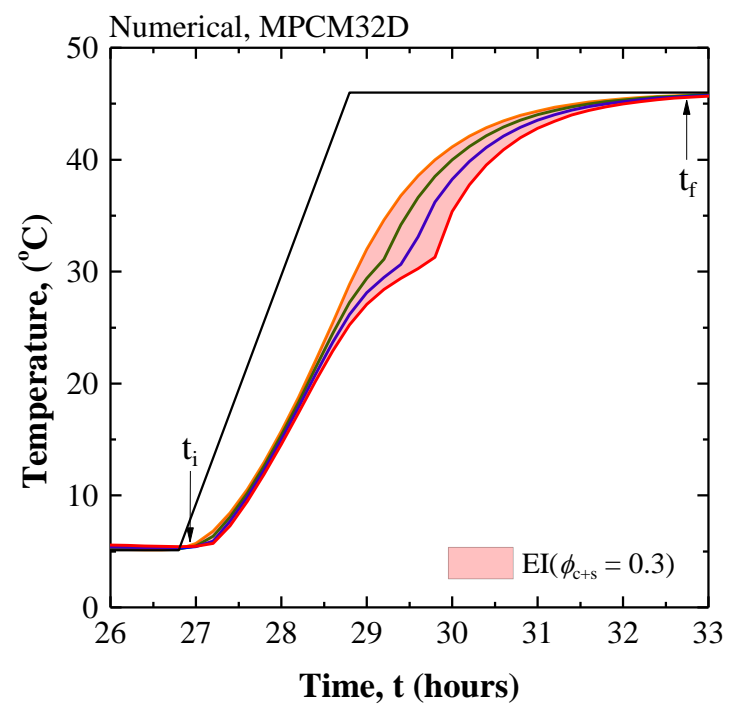

Figure 6: Centerpoint temperature $T_{c}(t)$ as a function of time within cement paste specimens without and with MPCM32D with volume fraction $\phi_{c+s}$ of $0.1,0.2$, or 0.3 subjected to an imposed chamber temperature $T_{\infty}(t)$ during cooling at temperature ramp rate of $20^{\circ} \mathrm{C} / \mathrm{h}$ (a) measured experimentally and (b) predicted numerically and also during heating at temperature ramp rate of $20^{\circ} \mathrm{C} / \mathrm{h}(\mathrm{c})$ measured experimentally and (d) predicted numerically. 
(a)

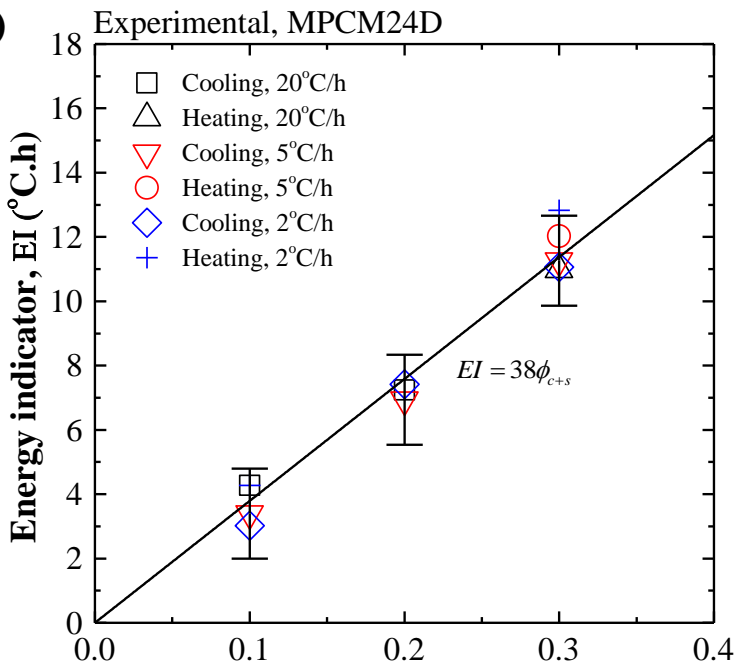

Microencapsulated PCM volume fraction, $\phi_{\mathrm{c}+\mathrm{s}}$

(c)

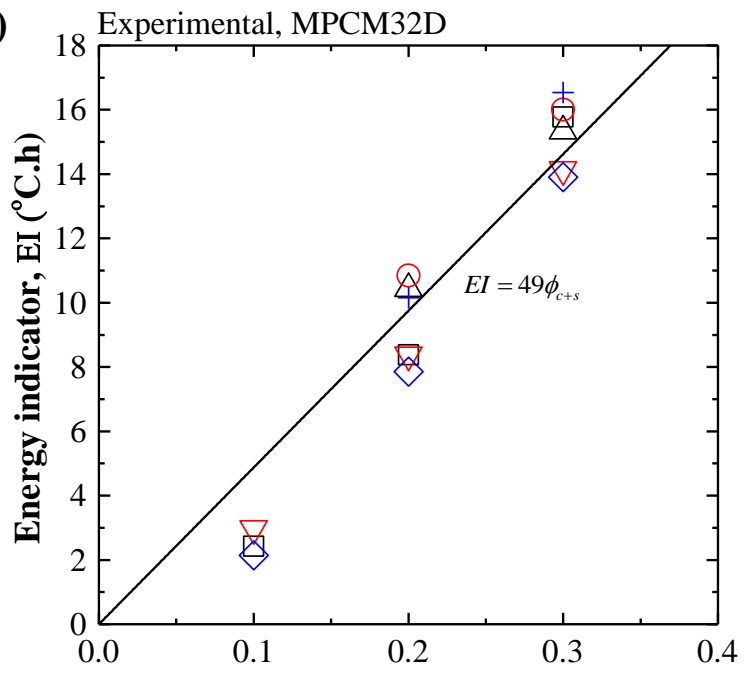

Microencapsulated PCM volume fraction, $\phi_{\mathrm{c}+\mathrm{s}}$ (b)

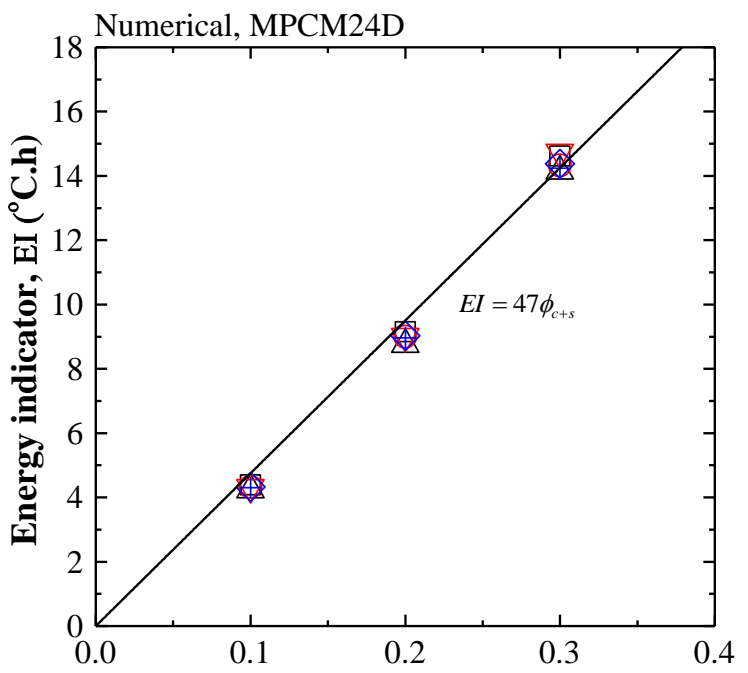

Microencapsulated PCM volume fraction, $\phi_{c+s}$

(d)

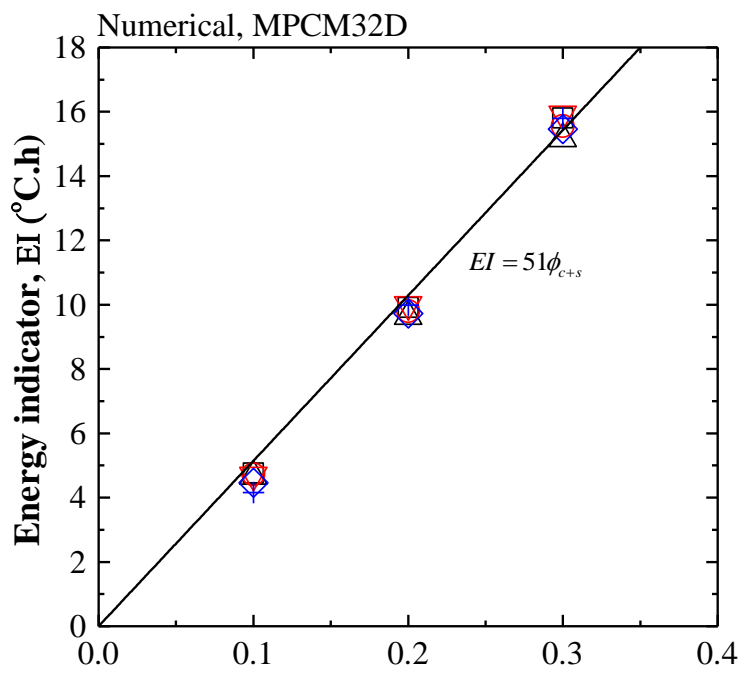

Figure 7: Energy indicator $E I$ as a function of microencapsulated PCM volume fraction $\phi_{c+s}$ ranging from 0.1 to 0.3 for microencapsulated PCM-mortar specimens subjected to heating and cooling at a temperature ramp rate of 20,5 , and $2^{\circ} \mathrm{C} / \mathrm{h}$ for (a) experimental measurements and (b) numerical predictions for MPCM24D and (c) experimental measurements and (d) numerical predictions for MPCM32D. The linear fits feature $\mathrm{R}^{2}$ larger than 0.98 . 
(a)

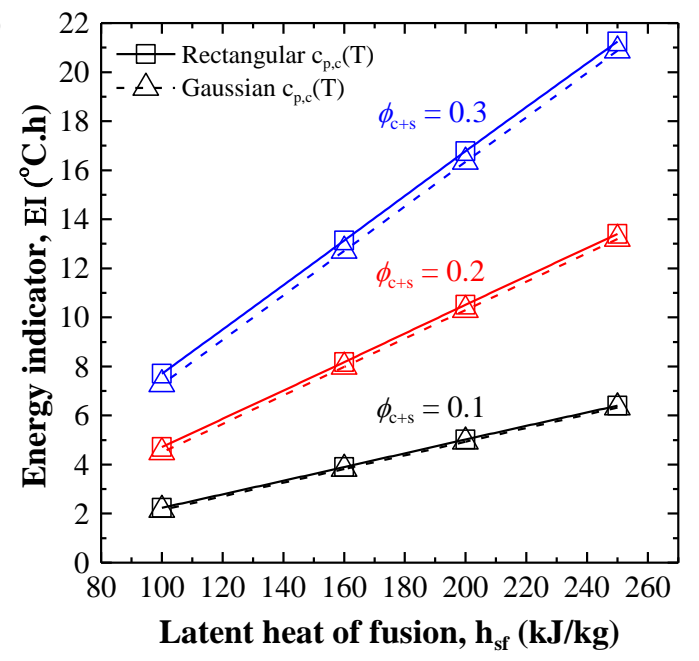

(b)

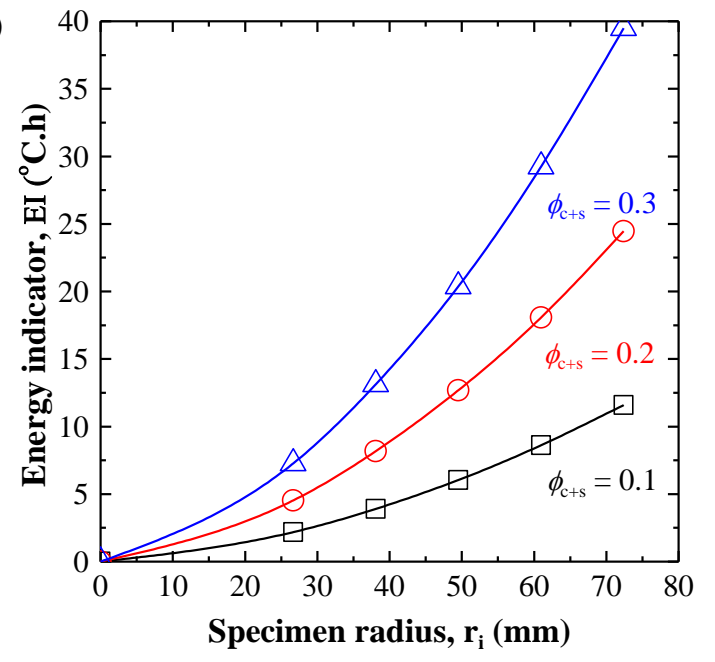

(c)

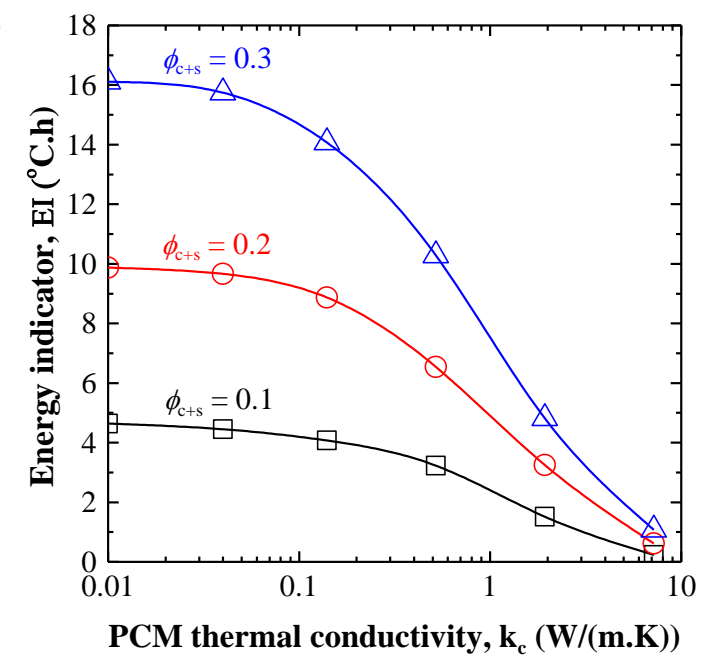

Figure 8: Energy indicator $E I$ as a function of (a) latent heat of fusion $h_{s f}$ ranging from 100 to $250 \mathrm{~kJ} / \mathrm{kg}$, (b) specimen radius $r_{i}$ up to $72 \mathrm{~mm}$, and (c) PCM thermal conductivity $k_{c}$ ranging from 0.01 to $10 \mathrm{~W} /\left(\mathrm{m}^{2} \cdot \mathrm{K}\right)$. Microencapsulated PCM volume fraction $\phi_{c+s}$ was taken as either $0.1,0.2$, or 0.3 . 


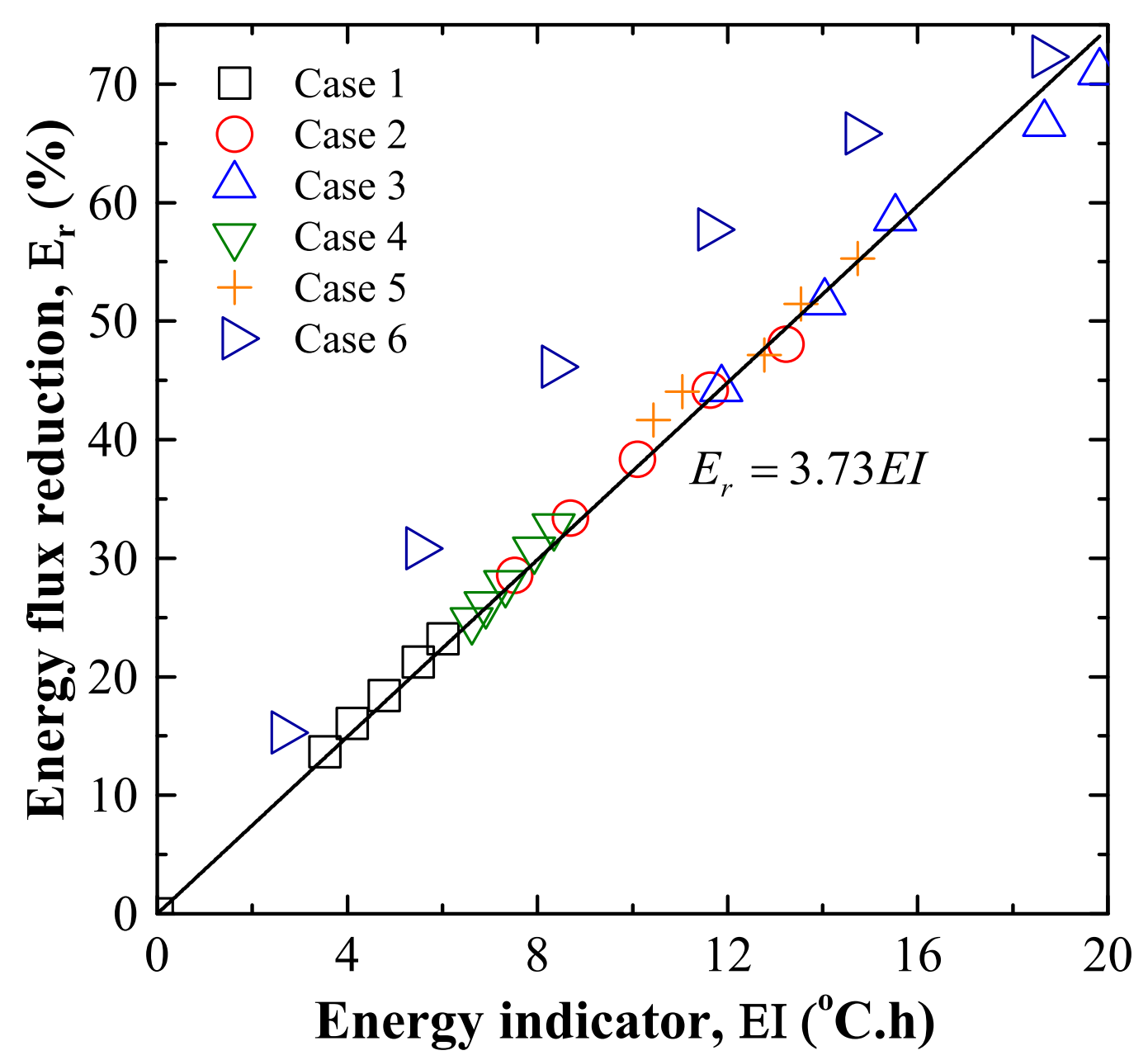

Figure 9: Correlation between the diurnal energy flux reduction $E_{r}$ achieved by a $10 \mathrm{~cm}$ thick PCM-mortar composite wall and the energy indicator $E I$ of a small specimen of the same material predicted numerically. The parameters corresponding to Cases 1-6 are summarized in Table 2. The microencapsulated PCM volume fraction $\phi_{c+s}$ ranged from 0.05 to 0.3 , the latent heat of fusion $h_{s f}$ from 100 to $200 \mathrm{~kJ} / \mathrm{kg}$, and the PCM thermal conductivity $k_{c}$ from 0.21 to $2 \mathrm{~W} /(\mathrm{m} \cdot \mathrm{K})$. The linear fit features $\mathrm{R}^{2}$ larger than 0.99 . 

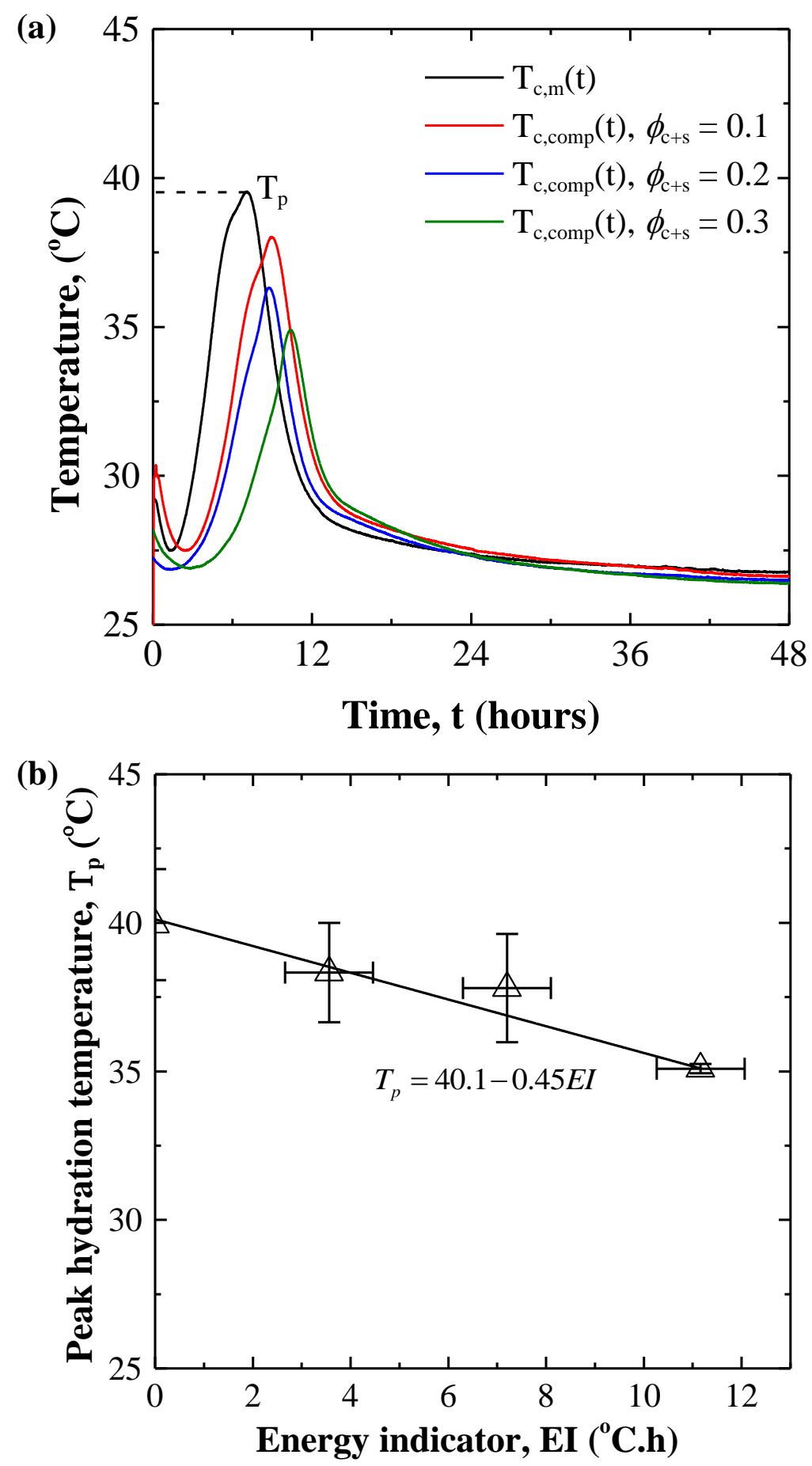

Figure 10: (a) Experimentally measured centerpoint temperature $T_{c}(t)$ as a function of time within cement paste specimens without and with MPCM24D at volume fraction $\phi_{c+s}$ of 0.1 , 0.2 , or 0.3 during the cement hydration period. (b) Peak centerpoint temperature $T_{p}$ reached during cement hydration as a function of the corresponding energy indicator $E I$. 